\title{
NUEVAS PERSPECTIVAS DE LAS FUENTES DE INFORMACIÓN PARA LA GEOGRAFÍA INDUSTRIAL*
}

\author{
José Luis Alonso Santos, Javier Aparicio Amador \\ y José Luis Sánchez Hernández \\ Departamento de Geografía, Universidad de Salamanca, Cervantes, 3. \\ 37008 SALAMANCA. Correo electrónico: vettonia@gugu.usal.es
}

\section{Introducción}

Durante las tareas de investigación que en los últimos años hemos realizado nos encontramos con satisfactorias experiencias derivadas de la mejora y diversificación de las fuentes de información, así como percibimos también la pervivencia de déficits y carencias, incluso el deplorable ocultismo de información básica por parte de las administraciones públicas. Pero además, hemos constatado que los profundos cambios producidos en el sistema productivo industrial reclaman nuevos métodos de investigación que, a su vez, entrañan nuevas formas de medición. Es decir, surge la evidencia de que las fuentes de información existentes -cuantitativas y cualitativashan de ajustarse a las nuevas realidades que también exigen el desarrollo de vías de análisis con carácter más cualitativo que cuantitativo. ${ }^{1}$

Las constataciones anteriores nos plantean tanto sugerentes interrogantes para la reflexión. ¿En qué grado, las fuentes existentes permiten estudiar la nueva realidad de la actividad industrial? O también, ¿en qué grado los geógrafos interesados en los estudios de Geografía industrial somos conscientes de que se imponen nuevos métodos de trabajo? ¿Qué lugar deben ocupar las fuentes de información en la formulación de esos métodos de conocimiento? Las páginas que siguen aspiran a contribuir al análisis y valoración de las fuentes de información, las posibilidades que ofrecen y las limitaciones o carencias que perviven.

* Este texto ha sido re-elaborado a partir de la ponencia presentada en las VIII Jornadas de Geografía Industrial (Zaragoza, septiembre de 2001). 
Cuando hablamos de fuentes de información nos referimos, en esencia, a una de las materias primas del conocimiento, al estado intermedio entre el objeto y el fenómeno que queremos conocer y el agente que pretende realizar esa comprensión, el investigador. En ese intermedio podemos utilizar varios pasos (el método de conocimiento), y en su seno se encuentran las fuentes que vamos a utilizar o a las que tenemos acceso para conocer el territorio.

Es importante, entonces, conocer las fuentes y su naturaleza, de cuántas disponemos o a cuántas tenemos acceso, si son o no fiables, qué variables aparecen, cuál su grado de fiabilidad, pero un paso previo es definir el método o modelo de conocimiento. Cómo nos vamos a acercar, cómo lo vamos a hacer para responder a las cuestiones que no conocemos previamente y a las que tenemos necesidad de contestar para conocer al objeto y sus interacciones con el entorno.

Podemos asimilar investigación con captura (figura 1), captura de información sobre algo que no se puede resolver o responder con los datos disponibles en ese momento, como nos indica Luis Miguel Barral (1998). El fin último de todo este engranaje no es, ni por lo más remoto, la captura de esa información necesaria, sino la solución del problema o la respuesta a esa pregunta inicial, la comprobación o refutación de la hipótesis de partida.

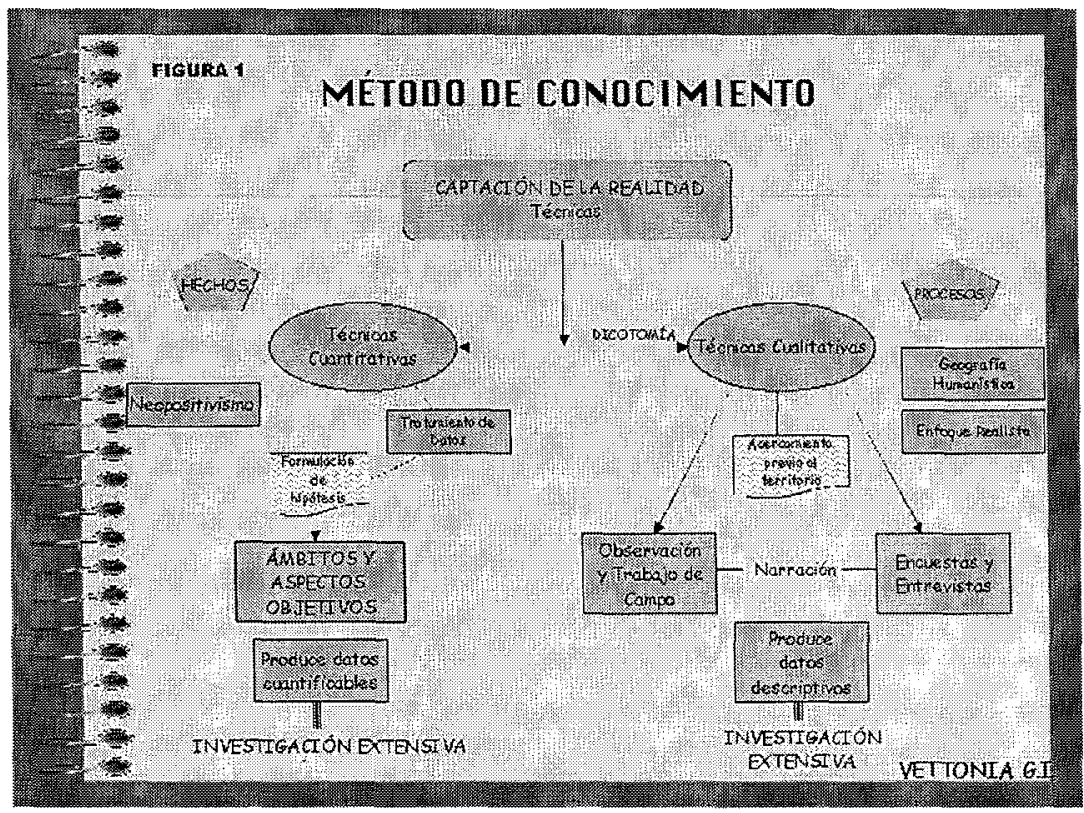

Figura 1 
Es probable que esta estructura de conocimiento o método de investigación nos haya llevado, históricamente, a ocuparnos más del punto de partida y del resultado que del camino intermedio que nos ha de llevar a ese conocimiento. Lo más habitual ha sido pasar de puntillas por los métodos y las fuentes que nos permiten capturar la información: el "vehículo" que nos transporta al conocimiento ha tenido, en la mayoría de los casos un tratamiento mucho más somero.

Podemos imaginar la captación de la realidad, tanto de la forma de los hechos y fenómenos como de sus procesos, como una especie de viaje desde el espacio vacío hacia el actor que lo habita y con el cual interactúa.

Ante todo este planteamiento, uno de los grandes problemas del geógrafo es la elección de las técnicas y fuentes necesarias y adecuadas para conocer e interpretar el entorno. En teoría, está claro que primero debemos tener definida una filosofía propia de conocimiento y una metodología que se adecue a nuestros presupuestos, y que esta delimitación nos llevará a las técnicas y fuentes que utilizaremos. Que nuestro pensamiento guiará nuestra forma de actuar o conocer. Pero en la realidad, el conocimiento de un territorio se tiene que hacer desde lo disponible, sin olvidar nuestra ideología.

Decidirse por un tipo de fuentes u otro generará una serie de consecuencias en la formulación de teorías y de interpretaciones, y en la recogida y tratamiento de los datos; ello determinará posteriormente el estudio que realicemos, el tipo de respuestas que podamos dar a las preguntas iniciales.

Así, queramos o no, estamos mediatizados por el enfoque inicial de nuestra ciencia. Bien nos dediquemos a investigar tanto la forma de un hecho o fenómeno, parte objetiva, bien a su proceso e interacción con el medio, parte subjetiva. Estamos obligados a utilizar diferentes y diversos tipos de herramientas.

Una parte muy importante del estudio es nuestro conocido "hombre habitante" que no siempre se amolda a parámetros totalmente cuantificables. Su relación con el medio es variable, en parte individual y en parte colectiva, y ese objeto de estudio, en el momento de la investigación, también se relaciona con el científico (investigador) y de esa relación, de su diversidad y de su sintonía sale una parte importante de nuestras interpretaciones.

Apoyándonos en estos presupuestos conceptuales, organizamos la Ponencia (figura 2) partiendo de una presentación retrospectiva de los trabajos que han reflexionado sobre las fuentes útiles para la Geografía Industrial en España. A continuación proponemos dos puntos centrales de exposición y debate: las fuentes estadísticas y las técnicas cualitativas. En tercer lugar, Internet aparece como un nuevo medio de acceso a la información que combina posibilidades cuantitativas y cualitativas y representa, a nuestro entender, un nuevo entorno operativo para la disciplina. Terminamos esbozando las posibles tendencias de futuro que pueden orientar la utilización de las distintas fuentes de información. 


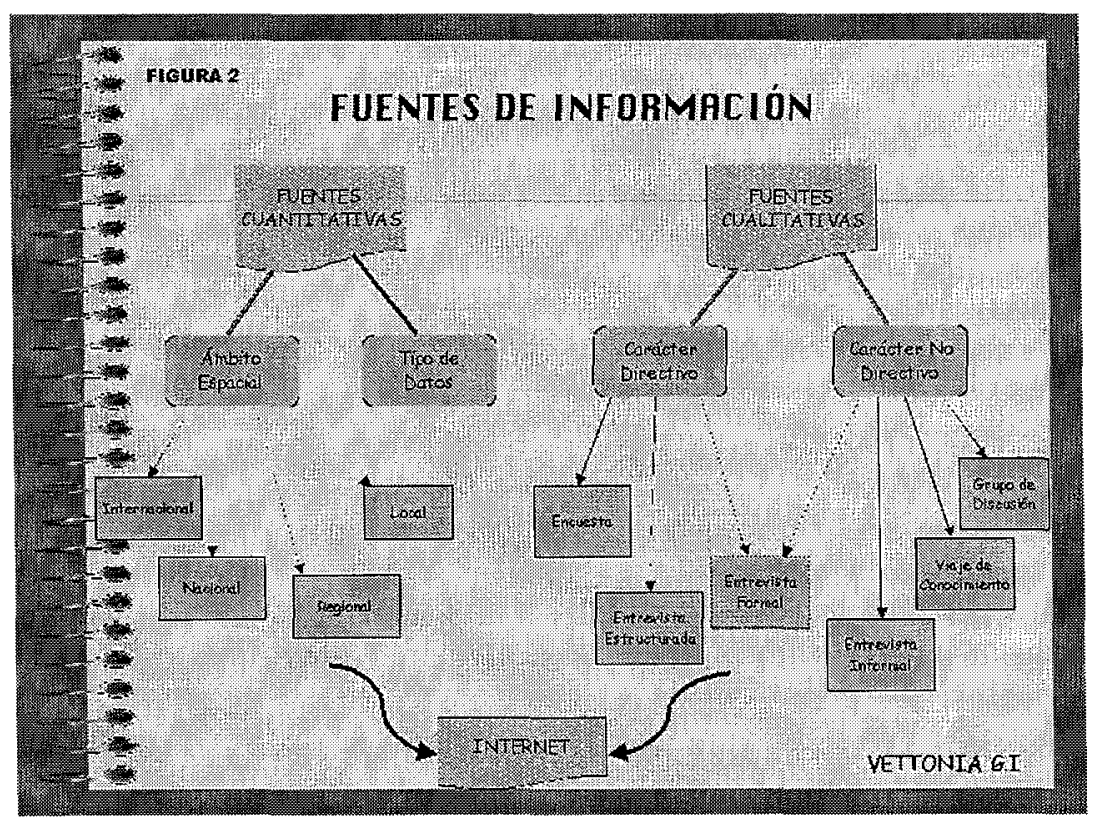

Figura 2

\section{Los estudios de Geografía Industrial en España: el análisis de las fuentes de información}

Los estudios de Geografía Económica en general y, en especial, los orientados al estudio de las actividades industriales han experimentado en la Geografía española un desarrollo notable en las últimas décadas a pesar de existir una escasa tradición en la comunidad universitaria española. Este desarrollo viene determinado no sólo por el incremento del número de investigadores y publicaciones sino, sobre todo, por los importantes cambios experimentados en el enfoque y los métodos de trabajo. Lógicamente, en toda actividad de investigación, uno de los componentes sustantivos sobre los que descansa la cantidad y calidad de la producción viene dado por la naturaleza de las fuentes de información. $Y$, en efecto, en esta ponencia intentaremos poner de manifiesto los cambios registrados, su naturaleza, en las fuentes básicas de información para el estudio de la Geografía Industrial. Sin duda, la irrupción de Internet será uno de los cambios de mayor impacto en la nueva etapa de las fuentes de información.

Si se nos permite una breve digresión retrospectiva debemos destacar que sólo en fecha tan reciente como 1958, España elabora el I Censo Industrial y será necesario que transcurran dos décadas (1978) para que se confeccione un II Censo Industrial. 
En esas fechas, la pobreza de fuentes de información es un lastre insalvable que, unido a la ausencia de tradición industrial del país, viene a reforzar la exangüe atención prestada a los estudios de Geografía Industrial por la comunidad universitaria hasta, al menos, los años setenta. La observación de manuales clásicos de la época en Geografía Económica o Regional ${ }^{2}$ permiten hacerse una idea bastante precisa de la situación existente. La parca variedad de los indicadores recogidos por las fuentes de la época imponía un tratamiento marcadamente cuantitativo, muy orientado a recrear la localización, describir el peso de las distintas ramas de actividad o el volumen de empleo. Bien es cierto que la relevancia adquirida por las actividades industriales, las políticas industriales seguidas, sus impactos espaciales y laborales, o los flujos de transporte asociados, así como su creciente peso en las exportaciones, se había incrementado de forma notable en los estudios regionales y urbanos que se venían haciendo en los últimos años sesenta. Se trataba casi siempre del análisis de la impronta espacial de sectores básicos como la industria minera, la energética o la siderurgia. En efecto, como bien ha destacado la Prof ${ }^{a}$. Caravaca, ${ }^{3}$ la creciente atención que se le presta desde los años sesenta a las actividades industriales con frecuencia aparece relegada a un segundo plano ya que forma parte de estudios más amplios bien de desarrollo regional bien urbanos.

No obstante lo anterior, el bagaje intelectual adquirido por el incremento de los estudios realizados directa o indirectamente sobre la industria tendrá un reconocimiento explícito en 1975 por parte de la comunidad geográfica, en el IV Coloquio sobre Geografia, que, bajo el significativo título de "Ciudad e Industria", estuvo dedicado al análisis industrial desde ámbitos diversos pero que hicieron posible un notable grado de reflexión y análisis sobre el tema que nos ocupa: las fuentes de información, su naturaleza, características de las mismas, nuevas posibilidades de la estadística o la informática, como apuntara el Prof. Regales, ${ }^{4}$ fueron aspectos que, por primera vez en la Geografía española, estuvieron en el centro del debate y la reflexión.

De la lectura de las ponencias y trabajos presentados en el IV Coloquio de Geografía así como de los pocos trabajos posteriores que han intentado explicar las endebles bases de la Geografía Industrial (Manero, 1992; Méndez, 1992), se pueden deducir algunas ideas dominantes referidas a la valoración de las fuentes de información.

En primer lugar, existe coincidencia entre los ponentes del IV Coloquio en resaltar las limitaciones existentes en la naturaleza, calidad y accesibilidad a las fuentes estadísticas, "muchas veces son desconocidas, casi siempre resultan inabordables, guardadas por el secreto de la empresa o por el de los organismos públicos" o “...en su mayoría las fuentes utilizables para la industria, aún las estadísticas asequibles, se caracterizan por su disparidad de criterios que obliga o impone elaborar estadísticas propias" (p.18), escribe literalmente J. Ortega y, a su vez, M. Ferrer dice textualmente “Por desgracia, en España se carece de estadísticas suficientemente desagregadas y fiables, lo que es un obstáculo para el tratamiento de los espacios industrializados" (p. 360). 
En segundo lugar, el Prof. Ferrer Regales avanza una rápida e interesante valoración de las principales fuentes estadísticas existentes poniendo de manifiesto lo que él considera sus mayores limitaciones y posibilidades para el objeto de estudio del geógrafo. En todo caso, de su valoración se puede inferir una disponibilidad de fuentes en ascenso y sin duda con posibilidades de utilización más intensas que las realizadas hasta el momento en los ámbitos regional y estatal.

Finalmente, aunque sea un aspecto cuyo alcance trasciende el estudio de las fuentes de información, sí nos parece importante resaltar la siguiente valoración que ambos ponentes realizan del desarrollo de la Geografía Industrial en España hasta el momento en el que escriben. Uno y otro concluyen que no se puede hablar de un campo de investigación consolidado en torno a la Geografía Industrial. No se percibe por entonces la existencia de un objetivo preciso en la investigación ni está clara la existencia de una metodología propia o apropiada que den la suficiente base teórica y metodológica a los estudios de Geografia Industrial, sostiene el Prof. J. Ortega en su ponencia.

Estamos pues ante un referente que, aún pudiendo entenderse como percepción de personas individuales, debemos considerar muy en serio quienes, aglutinados en el Grupo de Geografía Industrial (GGI), desarrollamos nuestra investigación en el ámbito de la Geografía Industrial. ¿En qué grado esa valoración podría extrapolarse al presente?; ¿en qué grado desde la creación del GGI hemos contribuido a la definitiva superación de esa pobre realidad?

Todavía en fechas tan cercanas a la actualidad como el año 1987, cuando tienen lugar las I Jornadas sobre Geografía Industrial, las fuentes de información siguen mostrándose como uno de los mayores obstáculos a superar para el avance de la Geografía Industrial. Al respecto, señalaba I. Caravaca (1987) en su comunicación "una parte de responsabilidad en el escaso interés despertado por la Geografía Industrial corresponde a las fuentes. Su escasez, imprecisión, falta de periodicidad e insuficiente desagregación constituye un importante obstáculo, con el que no es fácil enfrentarse, para el análisis de la industria" (p. 7).

Sin embargo, y a pesar de seguir existiendo limitaciones ciertas en las fuentes de información, es tan cierto o más que éstas se han perfeccionado, homogeneizado y ampliado notablemente, posibilitando un grado de análisis muy superior al que el Prof. Ferrer Regales describía todavía a mediados de los años setenta. Esta mejora cuantitativa y cualitativa de las fuentes de información lo es tanto en la escala local como en la regional y estatal debido al auge de las administraciones autonómicas y locales por un lado y a la necesidad de armonización con los indicadores de la Unión Europea por otro. Todo ello tendrá repercusiones positivas en la atención prestada a los estudios de Geografia Industrial a medida que avanzan los años ochenta como se han encargado de valorar los profesores Manero y Méndez, primero, y con una perspectiva temporal muy próxima han documentado las profesoras P. Benito y $\mathrm{H}$. Pascual (1998). 
Sin duda, la terrible crisis industrial (1975-1985) y la paralela tendencia a la especialización de los geógrafos, habrían fomentado el interés por los estudios en Geografía Industrial hasta el punto de pensar en constituir un grupo de trabajo dentro de la AGE. Creemos acertar al considerar el mero hecho de existir el grupo de trabajo (desde1986) como un factor importante de estímulo y consolidación de la investigación en Geografía Industrial. Desde entonces, los progresos realizados por los estudios de Geografía Industrial por encima de su dimensión estrictamente cuantitativa, pueden ser ponderados en la medida en que se realizan cada dos años las Jornadas de Geografía Industrial, las Jornadas de Campo también en años alternos, la aparición y consolidación de líneas estables de trabajo, respaldadas con numerosas publicaciones o la formación de grupos de reflexión orientados a mejorar y profundizar los conocimientos y métodos de trabajo de la disciplina. Sin duda, en todo ello, la búsqueda de una mejor utilización de las fuentes de información cuantitativas o la búsqueda y desarrollo de fuentes cualitativas, es una variable en absoluto olvidada y aspiramos a que esta ponencia y sus comunicaciones sean una nueva contribución en esa línea.

Con la crisis del modelo de producción fordista, a la Geografía Industrial, al igual que a otras muchas ramas del saber, se le presentan nuevos e importantes retos explicativos de las lógicas espaciales que se fraguan en la economía abierta y globalizada al verse obligados los distintos agentes sociales (ya sean públicos o privados) a diseñar estrategias de acción que conllevan interacciones espaciales nuevas. La búsqueda de respuestas a las nuevas lógicas espaciales de las relaciones económicas han estimulado los cambios en los métodos de trabajo en la Geografía Económica y han obligado a buscar e incorporar nuevas técnicas y fuentes de información. Así factores como la innovación, la internacionalización, la organización y cualificación del trabajo, el grado de concertación social de cada territorio (cuando no la "imagen" o los valores comunes), la cooperación entre empresas o las redes de cooperación, se convierten en factores determinantes para los estudios de la Geografía Industrial. Pero aprehender estas nuevas dimensiones no sólo requiere de la utilización de las fuentes estadísticas tradicionales, sino que exige el recurso sistemático a las fuentes de tipo cualitativo.

El análisis de los trabajos que se presentan a las sucesivas Jornadas de Geografía Industrial posibilita la valoración de los avances que se van pergeñando en la comunidad científica en torno a las nuevas formas espaciales de las actividades industriales. Una aproximación a las fuentes utilizadas en los trabajos presentados a las IIJornadas de Geografía Industrial (Santiago de Compostela, 1988) permite la ponderación de la situación existente en ese momento en cuanto a las fuentes de información para el desarrollo de los temas tratados. Entre las 22 comunicaciones presentadas a la Ponencia I, encontramos fuentes estadísticas de ámbito estatal, regional y local, pero también fuentes que aspiran a captar dimensiones más precisas, de carácter cualitativo, en las actividades industriales. En efecto, instrumentos de trabajo hoy frecuentes como la encuesta y la entrevista directa a los agentes empresariales aparecen en tres de las comunicaciones presentadas como fuentes de información básicas. 
Las fuentes estadísticas utilizadas y el grado de utilización que de ellas se hace viene recogido en el cuadro 1.

Cuadro 1. Fuentes estadísticas y grado de utilización

\begin{tabular}{|c|c|c|}
\hline Fuente & Organismo & Trabajos que la usan \\
\hline \multicolumn{3}{|l|}{ Ámbito estatal: } \\
\hline 1. Censo Industrial de España 1978 & INE & 1 \\
\hline 2. Registro de Establecimientos Industriales & MINER & 7 \\
\hline 3. Censo de Locales 1980 & INE & 2 \\
\hline 4. Registro de Empleo según cotizaciones a la Seguridad Social & I.N.S.S. & 2 \\
\hline \multicolumn{3}{|l|}{ Ámbito autonómico: } \\
\hline 1. Anuario Estadístico & C. de Madrid & 1 \\
\hline 2. Directorio de Establecimientos Industriales & C. de Madrid & 2 \\
\hline 3. Catálogo Industrial & $\begin{array}{l}\text { C. del País Vasco } \\
\text { Navarra }\end{array}$ & La Rioja, \\
\hline 4. Registro de Industrias Agroalimentarias & $\begin{array}{l}\text { C. de Castilla y } 1 \\
\text { Murcia }\end{array}$ & eón, \\
\hline 5. Registro Industrial Minero & C. de Murcia & 1 \\
\hline $\begin{array}{l}\text { 6. Asociación del sector de aserrería y fabricación de envases } \\
\text { y embalajes de madera }\end{array}$ & c. de Murcia & 1 \\
\hline \multicolumn{3}{|l|}{ Ambito local: } \\
\hline 1. Padrón de Licencias Fiscales & Ayuntamientos & 4 \\
\hline $\begin{array}{l}\text { 2. Registro municipal de actividades molestas, insalubres, } \\
\text { nocivas, peligrosas e inocuas } 1930-1987\end{array}$ & $\begin{array}{l}\text { Ayuntamiento } \\
\text { de Yuncos }\end{array}$ & 1 \\
\hline
\end{tabular}

Fuente: Elaborado por Vetona G.l, a partir de las Actas de las Ila Jornadas de Geografía Industrial.

Vemos que algunas de las principales fuentes estadísticas de ámbito estatal y regional son herramientas habituales de trabajo entre los geógrafos industriales así como en la escala autonómica aparecen fuentes de información de carácter sectorial (industria agroalimentaria, minera, madera) de gran utilidad para la investigación sobre los sectores de actividad incluidos. No obstante, nos consta que en el acceso a las fuentes de carácter regional y, sobre todo local, existían entonces y aún en la actualidad serias limitaciones, con lo que ello representa de obstáculo para la investigación o para llegar a valoraciones de contraste entre territorios a partir de los indicadores de esas fuentes. Limitaciones que podrían explicar la ausencia de algunas otras fuentes existentes.

\section{Las fuentes estadísticas}

\subsection{Las fuentes internacionales: breve comentario}

La creciente internacionalización de las economías en el mundo actual reclama cada día con más fuerza contemplar las actividades económicas por encima de las 
escalas locales e incluso nacionales. Y, una vez más, las fuentes de información se presentan como el referente de partida. A pesar de no ser el objeto de este trabajo, las fuentes de información internacionales disponibles para aproximarse al sector industrial nacional, debemos al menos mencionarlas ya que, además de aportar una información necesaria para valorar la escala de mercado de los distintos productos generados por la industria nacional, debería servir para animar a su utilización en futuros estudios de Geografía Económica. Por otro lado, resultan imprescindibles si queremos valorar la economía española en relación a sus socios y competidores internacionales.

Las fuentes de información internacionales de interés para la economía industrial española proceden de una variada gama de organismos que facilitan con regularidad información. Además de distintos organismos como Naciones Unidas, Banco Mundial y Fondo Monetario Internacional, con datos básicos generales o sectoriales por países, existen fuentes procedentes de organismos más especializados como la ONUDI, ${ }^{5}$ la Organización Mundial del Comercio (OMC) o la OCDE. Pero son las fuentes generadas por la Unión Europea (EUROSTAT) las que facilitan mayor grado de desagregación por actividades y territorios. Los indicadores regularmente emitidos por EUROSTAT son en la actualidad una fuente de gran importancia para el estudio de los distintos territorios (regiones, provincias o departamentos) de los países miembros así como para el seguimiento del comportamiento internacional de las economías nacionales y sus intercambios externos. No obstante, serán las estadísticas elaboradas por organismos públicos nacionales las que ofrecen un más amplio y detallado desglose de los indicadores para el estudio de los intercambios de la economía nacional con la internacional bien se trate de analizar el comportamiento de la inversión exterior (Banco de España: www.bde.es; Secretaría de Estado de Comercio: www.meh.es) bien de seguir el comportamiento del comercio exterior (Departamento de Aduanas e Impuestos Especiales. Ministerio de Economía y Hacienda: www.aeat.es).

En este marco de organismos y fuentes de información internacionales de utilidad para la Geografía Económica española no debemos omitir la importancia estratégica adquirida por la región latinoamericana para la economía española. También aquí encontramos una amplia referencia de organismos de carácter regional latinoamericano $^{6}$ (CEPAL, ALADI, SELA) de carácter de región económica de integración (MCCA, Comunidad Andina, CARICOM, MERCOSUR, NAFTA) o de cada país a través de los saldos exteriores de sus economías. Se trata de un amplio abanico de fuentes de información que permiten rastrear y evaluar la intensidad de los intercambios de la economía española con cada uno de los países de la región. En línea con el reconocimiento de la creciente relevancia que la internacionalización ha adquirido para las empresas nacionales, recientemente el INE ha diseñado una nueva encuesta con el significativo título de Indicadores de Globalización.

Las fuentes de información estadísticas no son tales si resultan inaccesibles al investigador. Esta obviedad parece superada en la actualidad para las fuentes de los 
organismos precitados ya que a la tradicional difusión en soporte papel se han unido el soporte en CD-ROM y, sobre todo, la consulta por Internet.

\subsection{La producción estadística industrial en España}

\subsubsection{La cuestión de la homologación internacional}

Un problema frecuente hasta fechas relativamente recientes en los estudios de Geografía Económica ha sido el derivado de la "discrecionalidad" de los autores a la hora de realizar clasificaciones de actividades o establecer escalas espaciales objeto de estudio. El problema ha sido de mayor relieve en los estudios de ámbito local al superponerse el uso de fuentes locales sin criterios homologados de clasificación de las actividades sobre la débil metodología existente para la búsqueda de criterios de clasificación que facilitaran la comparación a escalas más amplias. El resultado ha sido la precaria capacidad de realizar trabajos de síntesis o comparativos que permitan llegar a resultados conjuntos más allá de los trabajos concretos.

Lógicamente, ese déficit se ha ido superando tras el ingreso en la Unión Europea ya que las fuentes de información del Instituto Nacional de Estadística (INE) han debido adoptar los criterios de clasificación de actividades propios de la comunidad (Revilla, 1994) que, a su vez, los tiene armonizados con los organismos multilaterales; las fuentes de tipo regional y local han ido incorporando a su vez los nuevos criterios europeos y mundiales. La homologación de la estadística nacional impulsará la aparición de nuevas fuentes de información en la pasada década.

Precisamente, esta homologación de los indicadores de las fuentes de información abre definitivamente la opción del estudio de la creciente internacionalización de la economía española con criterios similares a los usados en los países de la OCDE. Se trata de una dimensión de la economía nacional a la que la Geografía Económica no ha prestado atención y entendemos que debe empezar a ser objeto de estudio dada su creciente relevancia para explicar la actividad económica de muchas de las empresas que operan en los distintos territorios del país.

\subsubsection{Las fuentes del sector privado}

A la hora de situarnos ante las principales fuentes estadísticas existentes debemos diferenciar entre las generadas por los organismos públicos en sus diferentes escalas de competencia y las emanadas de instituciones o empresas privadas. En efecto, el sector privado ha sabido implantar con solidez publicaciones bien conocidas desde hace décadas como La Renta Nacional de España y su Distribución Provincial, producida por el BBV ininterrumpidamente desde 1955; o el Anuario del Mercado Español (a cargo del antiguo Banesto); el Anuario Económico de España (La Caixa) 
ha venido a dar continuidad al anterior pero, a la vez, con la nueva dimensión de accesibilidad que las ediciones en CD-ROM e Internet confieren más recientemente a las fuentes de información. Otros informes periódicos como los de FUNCAS, CAMERDATA o ALIMARKET, son recursos estadísticos editados de creciente reconocimiento en la comunidad científica.

Pero la irrupción de Internet ha transformado radicalmente el mundo de la información y la forma de acceder a la misma. Y, en efecto, cada día es más amplia y variada la oferta de información estadística existente en la Red a cargo de empresas especializadas que, en contrapartida limitante en cuanto a la accesibilidad, tienden a reducir el acceso gratuito a la vez que las cuotas de acceso no siempre resultan asequibles para el investigador individual o incluso para buen número de investigadores con proyectos de investigación pero de limitada dotación económica. En casos en que la cantidad de consultas a realizar es grande, los costes de acceso a estas fuentes de información en la Red pueden resultar disuasorios por completo.

\subsubsection{Las fuentes industriales de la Administración Central}

El Instituto Nacional de Estadística (INE) es el gran centro de producción de indicadores para el estudio de las actividades económicas si bien las comunidades autónomas han ido adquiriendo un creciente protagonismo. En los dos últimos lustros, la cantidad y variedad de las fuentes de información de base industrial ha mejorado notablemente. No obstante, los técnicos del propio INE (Revilla,1994; Feito,1994) siguen poniendo el acento en la necesidad de ampliar y mejorar las fuentes de información a la vez que se hace necesario diversificar los métodos de observación de las actividades, en especial del sector de los servicios.

El cuadro 2, presenta las principales fuentes industriales, sus características fundamentales y la escala territorial. El abanico de fuentes va de las más básicas y generales con un grado importante de desagregación de la información, pasando por las referidas sólo a un sector o variable hasta las más recientes y especializadas. El interés para la Geografía Industrial lógicamente difiere de unas a otras ya que fuentes como Encuesta sobre Inversiones en la Industria, Sistema Integrado de Estadísticas Industriales, Indicadores sobre Globalización de las empresas, Incentivos Regionales, sólo ofrecen información a nivel del país y, en los dos casos últimos, no son accesibles bien por la inmediatez temporal de su lanzamiento (Indicadores de Globalización) bien por ser considerada en los organismos responsables como información de "uso interno" (Incentivos Regionales).

El grado de desagregación de la información aportada (por naturaleza de las actividades y número de variables) por cada fuente es un indicador determinante para la clasificación de las mismas respecto al interés final para el investigador. En este sentido, la calidad de las fuentes vuelve a ser muy contrastada como permite ver la obser- 
Cuadro 2. Fuentes estadísticas nacionales

\begin{tabular}{|c|c|c|c|}
\hline \multirow[b]{2}{*}{ Fuente } & \multicolumn{2}{|c|}{ Variables contempladas* } & \multirow[b]{2}{*}{ Desagregación Territorial } \\
\hline & Variables económicas & Variables de localización & \\
\hline $\begin{array}{l}\text { Encuesta Industrial } \\
\text { de Empresas }\end{array}$ & $\begin{array}{l}\text { Producción, ventas, } \\
\text { exportaciones, consumo } \\
\text { de energla y materias inter- } \\
\text { medias, inversión, empleo, } \\
\text { costes laborales y finales } \\
\text { CRUCE DE VARIABLES: } \\
\text { productividad, costes labo- } \\
\text { rales unitarios, competitividad, } \\
\text { rentabilidad }\end{array}$ & $\begin{array}{l}\text { Domicilio social de la } \\
\text { empresa / domicilio del } \\
\text { establecimiento }\end{array}$ & Autonómica \\
\hline $\begin{array}{l}\text { Encuesta Industrial } \\
\text { de Productos }\end{array}$ & Producción comercial y ventas, & $\begin{array}{l}\text { Domicilio del estable- } \\
\text { cimiento }\end{array}$ & Autonómica \\
\hline $\begin{array}{l}\text { Encuesta de Inno- } \\
\text { vación Tecnológica }\end{array}$ & $\begin{array}{l}\text { Gasto en innovaciones, innova- } \\
\text { ción, ventas productos nuevos, } \\
\text { difusión innovación }\end{array}$ & Muestreo de empresas & Autonómica \\
\hline $\begin{array}{l}\text { Indices de Producción } \\
\text { industrial }\end{array}$ & $\begin{array}{l}\text { Valor Añadido por ramas } \\
\text { de actividad }\end{array}$ & $\begin{array}{l}\text { Empresas y Estableci- } \\
\text { mientos }\end{array}$ & Autonómica \\
\hline $\begin{array}{l}\text { Impuesto de Activi- } \\
\text { dades Económicas } \\
\text { (IAE) }\end{array}$ & $\begin{array}{l}\text { Actividad, razón social, traba- } \\
\text { jadores, potencia instalada, } \\
\text { superficie, cuota del impuesto }\end{array}$ & Domicilio de la empresa & Municipal \\
\hline $\begin{array}{l}\text { Registro de Estable- } \\
\text { cimientos Industriales }\end{array}$ & $\begin{array}{l}\text { Actividad, inversión en capital } \\
\text { fijo, potencia instalada, empleo, }\end{array}$ & $\begin{array}{l}\text { Domicilio fiscal, domicilio } \\
\text { de la actividad }\end{array}$ & Municipal o inferior \\
\hline $\begin{array}{l}\text { Registro de la } \\
\text { Seguridad Social }\end{array}$ & $\begin{array}{l}\text { Actividad, empleo, } \\
\text { cotizaciones }\end{array}$ & Domicilio empresa & Provincial y municipal \\
\hline $\begin{array}{l}\text { Contabilidad Regional } \\
\text { de España }\end{array}$ & $\begin{array}{l}\text { I VAB, salarios, empleo, PIB, } \\
\text { formación bruta de capital }\end{array}$ & $\begin{array}{l}\text { Contabilidad regional y } \\
\text { local por ramas de actividad }\end{array}$ & Provincial \\
\hline $\begin{array}{l}\text { Encuesta de Pobla- } \\
\text { ción Activa }\end{array}$ & $\begin{array}{l}\text { Rama de actividad, cualifi- } \\
\text { cación, ocupación, tipo de } \\
\text { contrato de ocupados, parados } \\
\text { e inactivos }\end{array}$ & Muestreo de empresas & Provincial y municipal \\
\hline $\begin{array}{l}\text { Directorio Central } \\
\text { de Empresas (DIRCE) }\end{array}$ & 3 dígitos CNAE & Domicilio de la actividad & Municipal o inferior \\
\hline $\begin{array}{l}\text { Encuesta sobre in- } \\
\text { versiones en la } \\
\text { industria }\end{array}$ & $\begin{array}{l}\text { Inversión, expectativas, causas } \\
\text { y fines de la inversión }\end{array}$ & Muestreo en empresas & Nacional \\
\hline $\begin{array}{l}\text { Indicadores de } \\
\text { globalización }\end{array}$ & $\begin{array}{l}\text { Estructura de la empresa, } \\
\text { inversión, ventas, subcontra- } \\
\text { tación, empleo, gasto en } \\
\text { medio ambiente }\end{array}$ & Muestreo en empresas & Nacional \\
\hline $\begin{array}{l}\text { Sistema integrado } \\
\text { de estadísticas } \\
\text { industriales }\end{array}$ & $\begin{array}{l}\text { Las variables de la estadistica } \\
\text { industrial }\end{array}$ & Otras fuentes industriales & Nacional \\
\hline $\begin{array}{l}\text { Incentivos } \\
\text { Regionales }\end{array}$ & $\begin{array}{l}\text { Inversiones, creación puestos } \\
\text { de trabajo, subvención, } \\
\text { actividad }\end{array}$ & Domicilio empresa & $\begin{array}{l}\text { Uso interno del } \\
\text { Ministerio }\end{array}$ \\
\hline
\end{tabular}

*Nota: se refiere a las variables que figuran en los cuestionarios remitidos a las empresas o establecimientos y que se utilizan para la recogida y tratamiento de la información.

FUENTE: Elaborado por Vetona G.I. 
vación del cuadro 3. Pero además de la cantidad de información que ofrecen las fuentes interesa de manera especial su grado de desagregación espacial. Es decir, si la información puede medirse a escala general o estatal o también se presenta desagregada para las otras instancias político administrativas vigentes: la comunidad autónoma, la provincia y el municipio.

En efecto, la cuestión de la escala espacial constituye un factor de primer orden para los estudios de Geografía Industrial. Cuanto mayor sea la precisión de localización de las variables, mayor potencial de interpretación territorial de las actividades económicas podemos conseguir. Lógicamente, el número de fuentes que ofrecen información a escala local/municipal es reducido y reducido es también el número de variables que ofrecen para cada empresa. Por desgracia, seguimos careciendo de fuentes estadísticas en las escalas intermedias entre el municipio y la provincia, carencia compensada en otras áreas de información como sucede con las comarcas agrícolas o incluso con las áreas funcionales comerciales. Se trata de una carencia de muy graves repercusiones para los estudios de Geografía Económica ya que, siendo diferenciado en el espacio el comportamiento de los agentes económicos, la localización de las actividades tiende a la desconcentración, difundiéndose en el entorno rural y, paralelamente, en las áreas rurales se diferencian y jerarquizan los espacios que concentran actividades y los que carecen de las mismas. Todo ello demanda fuentes de información más acordes con esas dinámicas espaciales que, por ahora, no tienen respuesta. En cambio, el desarrollo de las autonomías ha llevado en la práctica al desarrollo de fuentes de información de ámbito autonómico y provincial de creciente calidad.

En esta línea, fuentes como el Impuesto de Actividades Económicas, el Registro Industrial, la Encuesta de Población Activa o el Registro de la Seguridad Social, permiten el estudio de las actividades industriales a escala municipal en las distintas ramas de actividad, si bien las variables que incorporan son reducidas (de 2 a 5) aunque importantes como indican los cuadros 2 y 3 . El INE sigue siendo el proveedor más universal de fuentes de información de escala regional a través primero de la Encuesta Industrial (1978) y desde 1993 con la Encuesta Industrial de Empresas y la Encuesta Industrial de Productos. Pero estas se han visto complementadas con otras fuentes más específicas que miden variables como las inversiones, la producción industrial o la innovación tecnológica. Así mismo, en la escala regional y también provincial la Contabilidad Regional de España es una fuente de información de gran importancia.

La Encuesta Industrial, de periodicidad anual, es una de las fuentes básicas para el estudio del comportamiento del sector industrial a partir del Censo Industrial de 1978. En la vida de la Encuesta Industrial se pueden distinguir dos fases temporales distintas ya que desde el año 1993, en línea con la búsqueda de su armonización con los parámetros utilizados por la Unión Europea, se reforma y mejora desdoblándose en dos encuestas complementarias: la Encuesta Industrial de Empresas y la Encuesta Industrial de Productos. 


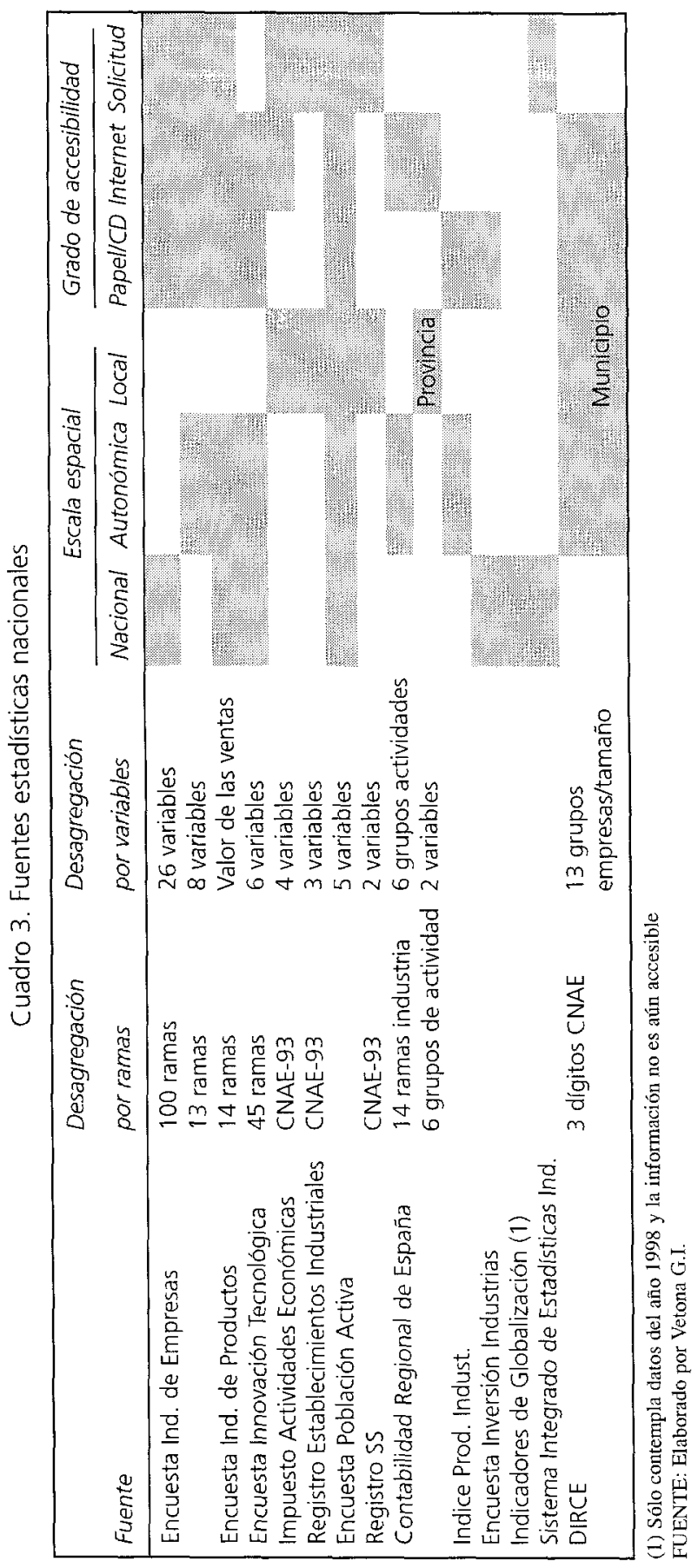


Se trata de dos encuestas muy distintas y a la vez se complementan ya que mientras la Encuesta Industrial de Empresas (Feito, 1994) recoge todas las variables posibles necesarias para valorar la actividad de la empresa (ver cuadros 2 y 3), la Encuesta Industrial de Productos se ciñe estrictamente a medir la producción comercial de los establecimientos o centros de producción y su valor en el mercado. Otra diferencia sustantiva entre ambas encuestas se refiere a la unidad base de referencia. Mientras la Encuesta Industrial de Empresas toma, en efecto, la empresa como unidad de referencia, en cambio, la Encuesta Industrial de Productos, parte del establecimiento o la unidad de producción.

Por último, cuando hablamos de las fuentes una dimensión sustantiva de las mismas es su accesibilidad. Y lamentablemente es una de las contingencias menos cuidadas por algunas administraciones que traduce en efectos negativos muy graves para el desarrollo de la investigación en general. Teniendo en cuenta ese viejo soliloquio que la información es poder, es difícil sustraerse a la idea de una Administración que gestiona la información de acuerdo con intereses burocráticos, siendo reacia a compartir unos datos que en última instancia son propiedad de la sociedad. Un ejemplo llamativo es el de los Incentivos Regionales, tratados con secretismo.

Lógicamente, la escala espacial a la que se trabaje y las variables a considerar serán determinantes para definir el grado de accesibilidad de las fuentes de información. Así mientras se trabaje con escalas y variables contenidas en las publicaciones -papel o CD- o en Internet, la accesibilidad se hace universal. Pero cuando se pretende trabajar a escalas espaciales más concretas o con más número de variables comienzan las complicaciones que en ocasiones pueden concluir en la inaccesibilidad de las fuentes. Mientras las fuentes controladas por el INE contemplan la opción de solicitar información específica desagregada en función de los objetivos de la investigación, hay otras como el Registro Industrial, que la responsabilidad de recogida de la información está en manos de las comunidades autónomas. Y no todas ellas tienen actualizada la información para facilitarla directamente o a través del Ministerio de Ciencia y Tecnología (anteriormente MINER). En otros casos, como sucede con fuentes como el Registro de la Seguridad Social, el acceso resulta muy restringido, si no imposible de no mediar relaciones personales. El Impuesto de Actividades Económicas, de gran utilidad en la investigación a escala local, presenta una accesibilidad muy aleatoria, ya que el talante de los responsables del servicio en ayuntamientos y cámaras de Comercio puede ser un factor determinante para acceder o no a la información.?

\section{El creciente siginificado de las fuentes cualitativas}

La necesidad de no quedarse en el hecho, en el fenómeno, en lo objetivo, impone el empleo de otro tipo de técnicas menos rígidas. La importancia de tener en cuenta 
los procesos, los aspectos subjetivos que nos ayudan a explicar las interacciones entre el territorio y el hombre parte de la fenomenología y el existencialismo dando lugar, en nuestra ciencia, a la Geografía Humanística.

Así, el interés que comienza a tener la intencionalidad de la acción humana, en las diferentes ciencias sociales, dentro del rechazo a la pura y fría objetividad, es lo que provocará la inicial atención hacia las fuentes cualitativas. Si queremos conocer e interpretar el mundo de lo social, debemos tener presente las dificultades que atañe entrar en el mundo de los significados, en un espacio que no definimos o delimitamos de forma cerrada con hipótesis previas, en el que estamos desde el inicio abiertos a asimilar e interpretar cualquier tipo de procesos que nos puedan explicar el territorio.

Es claro y notorio, para cualquier investigador, que en este tipo de conocimiento no se desarrollan una fuentes específicas ni para la Geografía socio-Económica ni para ninguno de los saberes de las Ciencias Sociales. Más bien existen una serie de "instrumentos" que son comunes a todos y que se utilizan y eligen teniendo en cuenta tres factores: la pregunta que se quiere responder, el tipo de población y/o medio al que se dirige la investigación y, muy importante en los momentos actuales, los medios de los que dispone el investigador, porque la obtención de información a través de alguna de las fuentes que vamos a reseñar es costosa en tiempo $\mathrm{y}$ efectivos.

A la formación intelectual recibida se acercan más la entrevista semiestructurada y la encuesta; a nuestra historia científica el viaje de conocimiento; siendo el grupo de discusión una novedad que nos ofrece enormes posibilidades y nos obliga a avanzar en nuestras técnicas. El mundo de las Ciencias Sociales, y en él nuestro segmento de conocimiento, se encuentra en continua evolución, y más si sólo se tiene en cuenta el conocimiento de lo cualitativo.

Para Ruiz Olabuénaga e Ispizúa (1989), cualquier metodología de base cualitativa debe sustentarse en cinco fases de conocimiento:

1. Definir el problema, cuáles son las preguntas sin contestar.

2. Diseñar la investigación. Qué tipo de fuentes vamos a utilizar, a cuáles tenemos acceso de forma factible, qué técnicas de autoinformación podemos practicar sobre el territorio. Conviene abordar el problema de los indicadores de entornon desde el punto de vista de las propias vivencias del Hombre que habita el territorio.

3. Recoger los datos, con qué medios contamos, cómo vamos a procesar los datos

4. Analizar los datos 
5. Validar la investigación, proponer una teoria o conclusiones comprobables, y exponer sus resultados.

Todo es un proceso complicado, por lo abierto y no delimitado; un método que ha necesitado históricamente hacerse con un espacio entre las ciencias, digamos, más "Solventes". Es más fácil realizar y, sobre todo, sustentar afirmaciones a través de una metodología positivista, que desde la fenomenología. Todo ello nos obliga, en una ciencia de carácter social como la nuestra, a validar lo más fehacientemente posible nuestras interpretaciones. Para ello, John Eyles (1998) marca una serie de pasos:

1. Realizar postulados de suficiencia: hacer entender lo que se expone en la interpretación.

2. Consistencia lógica: interpretar los fenómenos de forma lógica y, siempre, en un contexto amplio.

3. Interpretación subjetiva: cualquier interpretación que hagamos tendrá en cuenta al sujeto.

Otro problema importante que cuestiona la consistencia científica de estas metodologías es la medición. Si medir, como nos dice A. Bailly (1998), es atribuir número a los elementos según ciertas modalidades precisas y estables o ver cuántas veces está contenida la unidad en algo, todo aquello relacionado con la subjetividad tiene una difícil precisión o medida.

¿Cómo evaluamos de forma fidedigna y precisa los datos de índole cualitativa? ¿los podemos sistematizar? ¿qué método utilizamos? Éstas y otras preguntas tienen, como era de esperar, difícil contestación, al menos de una forma precisa. Al final, aunque la información sea netamente cualitativa, su tratamiento debe tomar un cariz cuantitativo, procurando, consciente o inconscientemente que se acerquen a una forma precisa y delimitada, que dé firmeza a nuestras aseveraciones. Aún así, el abanico de interpretaciones, en cierta medida, se abre con este tipo de metodología, respecto a las de indole positivista.

Realizar un tipologia de este tipo de fuentes nunca ha sido fácil, no sólo por su diversidad, también por los agentes que intervienen en ellas y por ser uno de los campos más novedosos del mundo científico. Como siempre, dependiendo del criterio que utilicemos o que prioricemos tendremos un tipo de clasificación diferente.

La más universal, en esta interacción entre el investigador y el individuo-colectivo habitante, es la que mide por un lado la forma en la que se realiza la "captura" y por otra el grado de libertad que otorga el investigador al investigado en sus respuestas. 
Así dividimos las fuentes entre las que tienen un carácter directivo y las que no lo tienen, o al menos dejan al interlocutor una mayor libertad para proyectarse sobre la investigación.

De carácter directivo son las encuestas y las entrevistas estructuradas, mientras que de carácter no directivo son las entrevistas no formales o libres, los viajes de conocimiento y los grupos de discusión. En un punto intermedio, entre las dos categorías nos encontraremos con las entrevistas formales o semiestructuradas, que parten de un esquema preestablecido, pero cambian según el desarrollo de la entrevista o el carácter del entrevistado.

\subsection{Fuentes de carácter directivo}

Realizaremos un análisis descriptivo de las principales fuentes cualitativas yendo desde las más dirigidas y cerradas a las más libres y abiertas.

\subsubsection{Las encuestas.}

Para definir estas fuentes podemos partir del concepto de Ángela Redondo (Ángela Redondo, 1998, pág. 54), que entiende por encuesta «el conjunto de métodos, generalmente estadísticos, que permiten el estudio sistemático de determinados problemas (generalmente sociales y políticos) con el fin de reunir éstos, observaciones rigurosas y formular hipótesis que puedan explicar los hechos observados". Teniendo presente, claro está, que ese "conjunto de métodos" a los que se refiere la autora son los que están delimitados a una serie de preguntas a las que el interlocutor responde por escrito, en cualquier tipo de soporte.

Es la fuente cualitativa más sistemática, pudiéndose tratar en algunos casos la investigación como cuasi-cuantitativa, todo dependerá

- de la muestra, del porcentaje de encuestados, cuanto más se acerque al total mayor será su tratamiento cuantitativo y su supuesto rigor científico; cuanto más débil sea dicho porcentaje más abierta podrá ser su interpretación y mayor la obligación de utilizar las normas que marcan las teorías sociológicas y que tan "extrañas" son, en muchos casos, al mundo y a la formación académica del geógrafo.

- del tipo de preguntas, lo normal es diseñar un tipo de preguntas cerradas, en las que el encuestado puede elegir como respuesta una de las opciones, dejando como preguntas abiertas, de libre contestación entre el 10 ó el 15\%, aunque en algunos casos no se deja abierta ninguna de las preguntas. También 
es verdad que hay encuestas abiertas, con un grado de preguntas de respuesta abierta alto, que normalmente responden a colectivos muy identificados $\mathrm{y} / \mathrm{o}$ comprometidos en un tema, además de poco numerosos.

- del grado de respuesta, del tanto por ciento de respuestas conseguidas. Se considera que en poblaciones pequeñas el número de encuestados debe ser de casi el $100 \%$, disminuyendo a la vez que aumenta el colectivo, aunque a la vez que dicho número crece el muestreo no puede ser discrecional, sino debe estar dirigido, teniendo en cuenta los diferentes grupos que componen el conjunto.

- y, sobre todo, de la sinceridad del encuestado. Nuestra experiencia nos dice que los colectivos más "sinceros", los que ven más necesarias este tipo de investigaciones, son los más "innovadores", los que identifican información y conocimiento, y éstos con desarrollo e innovación. Los sectores más maduros, en lo que normalmente luchan por hacerse con un hueco compitiendo en precio, la información se tiene casi como secreta, considerando, casi siempre, este tipo de investigaciones como "molestas" y hasta algo peligrosas para su futuro.

La encuesta precisa de un trabajo minucioso en el que podemos diferenciar cuatro etapas:

a. Elaboración. El trabajo previo es muy importante, hay que acercarse al segmento productivo que queremos conocer. Las preguntas iniciales nos deben llevar a conocer la población encuestada (direcciones), problemas generales, futuro, otros colectivos y territorios más avanzados. Al fin y al cabo se trata de recoger información sobre el tema, un estado de la cuestión que nos permita acercarnos al territorio con alguna hipótesis previa.

b. Cuestionario. Su redacción supondrá el punto clave de la investigación, de ella dependerá en buena parte el éxito del trabajo. Una vez que tenemos clara a qué población nos dirigimos, cómo es y cuál es su número, tenemos que decidir qué tipo de preguntas queremos o debemos hacer, cerradas o abiertas, con datos cuantitativos o más cualitativos. Dichas preguntas deben ser claras y sencillas, tanto desde el punto de vista lingüístico, como desde el subjetivo, consiguiendo así un Precuestionario, sobre el que discutirá el equipo, haciendo una serie de pruebas que nos puedan dar los problemas con los que se encontrará el encuestado. Todo este proceso nos lleva al Cuestionario.

c. Trabajo de campo o de despacho, según procedamos en la investigación. Lo primero es decidir el tipo de muestreo que vamos a realizar, dependerá del dinero con el que se cuente y del tamaño de la población que queremos conocer. Así llegamos al tamaño de la muestra que vamos a utilizar, decidiendo a continuación cuál será el método de realizarla, lo más habitual es el envío por 
correo, siendo un buen punto de partida adjuntar una carta de presentación de alguna asociación o directivo que represente a ese colectivo. Cuando el número de encuestas es reducido, y el dinero disponible lo posibilite, se puede realizar por medio de visitas, lo que nos dará, en general, un grado de fiabilidad y de respuesta mayor. Acercándose este último método a la entrevista dirigida o estructurada, siendo su única diferencia su extensión. El tiempo de realización debe ser corto, cualquier circunstancia externa o interna que introduzca alguna variante en las contestaciones invalidaría todo el trabajo.

d. Tratamiento de los datos. Lo que podemos denominar la labor sorda, el trabajo que necesitamos para poder utilizar toda la información que obtenemos de la encuesta, para que esos datos nos lleven a formular una serie de respuestas que contesten a la pregunta inicial. La presentación de dichos datos se hará de una forma totalmente cuantitativa, lo que puede dar al trabajo de una "patina" cientifista.

La encuesta es, probablemente, la fuente cualitativa más utilizada en los últimos años por los trabajos de investigación de la geografía económica. El tipo de fuentes estadísticas al uso en el país, su periodicidad, los últimos años (normalmente de años atrasados), y sobre todo sus carencias, falta de rigurosidad en algunos casos y ausencia de variables en la actualidad importantes, ha hecho de la encuesta un recurso necesario para el conocimiento. Por ello sería necesaria una mayor preparación por parte del geógrafo.

\subsubsection{Las entrevistas estructuradas}

Consideraremos como entrevista aquella conversación entre dos personas sobre un determinado tema. Si tenemos en cuenta la definición de la Real Academia introduciríamos dos opciones, que dicha conversación se da en un "lugar determinado", con lo que incide sobre el clima de la charla, y que suele tener como fin la "resolución de un negocio", aunque no se trate de una negociación propiamente dicha, sí es cierto que este procedimiento lleva al entrevistador a un mayor conocimiento y, por lo tanto, a resolver parte de sus preguntas. En la definición de Delgado y Gutiérrez (1995), citada en la comunicación de nuestra compañera Rosa Mecha, se hace hincapié en la selección previa del informante en función del papel que desempeña en el tema y en la libertad que éste tiene al contestar un guión previamente preparado de preguntas amplias.

Es una de las fuentes más interactivas, junto con los grupos de discusión, teniendo en cuenta que los dos agentes son actores en el momento de la conversación, dándose una retroalimentación constante entre los dos.

Las clasificaciones realizadas sobre esta fuentes suelen incidir principalmente en la variable ya utilizada en la ponencia del dirigismo del preparador a la hora de reca- 
bar la información. Dirigismo del entrevistador y libertad del entrevistado, de una forma enfrentada, nos darán los principales tipos de entrevistas que se utilizan en las Ciencias Sociales y que nosotros hemos reducido a tres, aunque algunos autores amplian a seis.

\section{Entrevista estructurada}

1. Entrevista estandarizada o formal

\section{Entrevista no estructurada o informal}

La primera tiene un carácter fundamentalmente directivo, incluida en este apartado, en la tercera predomina la libertad del entrevistado, mientras que en la segunda no predomina ni el entrevistador, directivo, ni el entrevistado, no directivo, encontrándose en tierra de nadie o participando de los dos supuestos.

La entrevista estructurada, para algunos denominada estandarizada cerrada (Rosa Mecha), es la que se basa en una serie de preguntas cerradas, que son las mismas para todos los entrevistados. Es el tipo que más se acerca a la encuesta, "facilitando la normalización de los resultados, su tabulación y permitiendo obtener unos valores estadísticos de referencia", como indica Ricardo Méndez en su comunicación, que nos permitirán extraer conclusiones objetivas.

Llevar a la práctica este tipo de técnica es muy complicado, lo más normal, lo que nos dice nuestra experiencia es que se acaba más bien en un guión de preguntas cerradas, pero con contestaciones más o menos abiertas, teniendo dos en una. Por un lado, cuantificaremos las respuestas cerradas, que era nuestra pretensión, pero a la vez, iremos conociendo el terreno de la mano de los comentarios "libres" hechos por el entrevistado.

\subsubsection{Entrevista estandarizada o formal}

También denominada semiestructurada, intensiva o basada en un guión, se sitúa a medio camino entre las fuentes directivas y las no directivas. En ella pesa tanto el papel director o dirigista del entrevistador como la libertad del entrevistado para introducir elementos personales o biográficos, como dicen algunos especialistas, en la conversación. Este tipo de entrevista es el preferido por las metodologías de tipo realista (Pratt, 1995).

Se basa en un listado de temas y cuestiones que se le van formulando al interlocutor según se vaya desarrollando la conversación, incidiendo más en unos puntos, dejando la suficiente libertad para que nos vaya trasmitiendo un estado de la cuestión que nos permita hacernos una idea clara del tema, influyendo posteriormente en 
las preguntas o cuestionario que le formularemos a otros interlocutores. Podemos indicar dos variantes,

- Una en la que el guión o listado de preguntas es igual para todos los entrevistados, teniendo éstos libertad en las respuestas;

- Y otra, en la que el guión se va cambiando en la propia entrevista, adaptándose a las contestaciones que nos da el interlocutor.

Todos, o la gran mayoría, coincidimos que este tipo de entrevistas es ideal para personas que tengan un peso específico dentro del territorio investigado, o por ser agentes locales y sociales o por ser empresarios innovadores, pioneros; dándonos una panorámica del conjunto.

Es una técnica, como indica Ricardo Méndez citando a Delgado y Gutiérrez (1995), que tiene una doble función, al permitir una recogida de datos y una recogida de discursos, de biografias, o de acciones, como indican otros autores próximos al postmodernismo (Gibson-Graham, 2000).

\subsection{Fuentes de carácter no directivo}

Consideramos aquí todas aquellas fuentes cualitativas en las que, dentro de la interacción que todas suponen, prevalece la libertad de respuesta del entrevistado sobre la dirección y preparación previa del entrevistador. Es el interlocutor el que varía y lleva la acción, siempre dentro del pretendido dirigismo del investigador, pero intentando abrir el esquema a temas y cuestiones que puede que no se hayan tenido en cuenta, o por desconocimiento o por falta de importancia previa.

\subsubsection{Entrevista no estructurada o informal}

También llamadas abiertas, no directivas o conversacional informal, son aquellas en las que a partir de unas cuestiones generales, siempre en relación con el tema, se va estructurando "in situn una entrevista. Se marcan una serie de cuestiones más o menos abiertas y la conversación va derivando hacia una serie de aspectos siempre al hilo de las respuestas del interlocutor, sin olvidarnos nunca que la batuta del investigador no puede perder nunca las riendas.

De todas formas, la charla no es completamente espontánea, se debe basar siempre en un trabajo previo, en un conocimiento que permitirá al entrevistador dirigir, sin parecerlo, el tema, aprovechando la libertad del entrevistado, que se acercará a una auténtica biografía, lo que denominan algunos bistorias de vida. 
Es muy conveniente acudir a este tipo de entrevistas en los primeros momentos de la investigación, porque nos ayuda a conocer el territorio que queremos investigar, a acercarnos a todos los intangibles que no aparecen en las fuentes estadísticas al uso y que son muy necesarios tener en cuenta a la hora de formular cuestionarios o preguntas dirigidas que luego podremos computar. Por todo ello, la población ideal para este tipo de conversaciones serán los agentes socioeconómicos, representantes de asociaciones o empresarios pioneros, quizá también alguien que se encuentre fuera de la estructura social pero que la conozca bien.

La complicación de esta fuente es su sistematización. Es tan subjetiva que no puede ser la norma, sino la excepción que nos permita después realizar otro tipo de prospecciones. Hay que tener siempre presente que las palabras y las opiniones, a diferencia de los números, carecen, en principio, de fronteras nítidas en su significado, prevaleciendo la interpretación subjetiva y contextual. Si no queremos perder la perspectiva que debe tener todo investigador, no debemos abusar de este tipo de conocimiento.

\subsubsection{Grupos de discusión.}

Es una técnica novedosa, en los últimos años se ha puesto en funcionamiento, que consiste en realizar grupos de conversación, en los que agentes socioeconómi$\cos$ que tienen que ver con el territorio que queremos estudiar, charlan sobre el estado de la cuestión.

El objetivo de esta técnica es "detectar los estados de opinión más ocultos", siguiendo a Barrall, 1998. Fin que en un principio puede parecer pretencioso, por lo que necesita un trabajo previo intenso. El analista tiene la obligación de autoanalizar previamente sus posiciones, eliminando prejuicios propios, una vez que tiene un conocimiento del espacio.

Debemos preparar las reuniones de forma minuciosa, es tan importante el espacio elegido para la conversación (aséptico, sin ninguna referencia para los interlocutores) como la preparación del, podríamos llamarle, "moderador" (no debe influir demasiado en los derroteros de la charla, pero tampoco puede permitir que derive hacia temas que no nos interesan). Parte del éxito de los resultados del grupo o grupos de discusión viene de la elección y distribución de los agentes en los diferentes conjuntos. Primero debemos tener en cuenta que en cada grupo es preciso reunir a personas de una condición socioeconómica similar, pues en su seno debe generarse una conversación "entre iguales", se consideran las mejores condiciones para llegar a las percepciones más ocultas. Todo nos llevará a montar varios grupos de discusión, uno por cada segmento poblacional o socioeconómico. 
Las conversaciones deben grabarse y después transcribirse para poder sacar conclusiones y sistematizarlas de alguna manera. Gran parte de los activos deben dedicarse a esta labor, que asumirá gran parte de nuestros esfuerzos.

Con esta fuente lograremos pulsar a los diferentes estados de opinión que hay en el territorio, que responden a diferentes motivaciones y vivencias. El aprehender procesos que conforman hechos no precisa necesariamente de una representatividad numérica homogénea o numerosa, ya que no pretendemos la inferencia estadística (aunque en muchos casos procuramos presentar los resultados como objetivos), queremos conocer las motivaciones, detectar los posicionamientos de la población y sus grupos. Así el grupo de discusión nos permite un conocimiento profundo de lo subjetivo del espacio.

\subsubsection{Viajes de conocimiento}

Esta es una de las técnicas de conocimiento geográfico más antiguas (Gómez Mendoza y otros, 1988). Para conocer un territorio desde los clásicos hasta la primera mitad de siglo xx se han utilizado principalmente las crónicas que se escriben a partir de viajes realizados por todo tipo de profesionales, tanto aventureros como soldados, embajadores; visitaban nuevos territorios sobre los que escribían una serie de relatos que servían a los geógrafos para sus obras, cuando éstos no eran los que viajaban para conocer el espacio.

El conocimiento directo de un lugar ha sido durante muchos años la base de cualquier obra geográfica, aunque no ha desaparecido, sí ha pasado a un segundo lugar en la metodología geográfica. La continua búsqueda de un reconocimiento científico por parte de la Geografia la ha llevado hacia derroteros preferentemente cientifistas, asumiendo métodos y técnicas de otras ciencias que tienen mayor entidad, al menos en teoría. Todo esto nos ha llevado a perder parte de nuestra entidad y nuestros orígenes, que deberíamos empezar a recuperar, y en este proceso estaría lo que podemos denominar como Viaje de Conocimiento.

Un proceso de conocimiento geográfico que también denominamos trabajo de campo y nos va a permitir, siempre de una forma subjetiva, conocer un espacio a través de la visita al territorio y de trabar una relación entre él y el investigador.

El viaje de conocimiento consta de varias fases de trabajo, como nos indica Lluis Mallart (1997)

1. Escoger. Documentarse previamente, como paso para llegar a conocer y entender un territorio.

2. Conocer. Experimentar, visitar y entablar una relación con el espacio, siempre desde la subjetividad, como único método geográfico que nos permite com- 
prender un territorio, sin olvidar que las demás técnicas nos ayudan a llegar a este estado del conocimiento.

3. Recordar. Realizar un tratamiento de los datos aportados por la realización de la técnica, pero también, y más importante será reflexionar sobre lo conocido, aprehenderlo.

La visita al espacio que queremos conocer nos resulta imprescindible en cualquier metodología de conocimiento geográfico, sin despreciar todas aquellas técnicas que hemos ido haciendo nuestras en estos años y que nos han ayudado a hacer de nuestro saber un reputado y válido método de conocimiento del territorio, a planificarlo y explicarlo desde el hombre.

\section{El «Tercer Entorno» como nuevo ecosistema para la Geografia Industrial}

\subsection{Una perspectiva teórica}

El filósofo Javier Echeverría ha propuesto la metáfora del "Tercer Entorno" (E3) para denominar al nuevo ámbito de relaciones humanas (sociales, políticas, económicas, personales) que se está constituyendo en torno a las redes telemáticas y, sobre todo, a Internet. Su trilogía "Telépolis", "Cosmopolitas Domésticos" y "Los Señores del Aire. Telépolis y el Tercer Entorno" imagina el ciberespacio como una ciudad donde habitamos los individuos y las organizaciones que participamos también de la vida en los entornos geográficos tradicionales (el medio natural - E1-y el medio urbano - E2-). Frente al carácter tangible y corpóreo de la naturaleza y la ciudad, la novedad decisiva del Tercer Entorno radica en su materia prima constitutiva, la información codificada en formato electrónico y plasmada en textos, imágenes y sonidos a los que, sobre el papel, puede accederse desde cualquier lugar del mundo. Una vez depositada en los discos duros de los servidores, la información queda a disposición de los teleciudadanos para su consulta, bien libre o bien restringida al pago de una cantidad de dinero, a la pertenencia a una organización determinada o a la simple inscripción como cliente en la base de datos del servidor que gestiona el flujo de los bytes.

La Telépolis de Echeverría constituye un nuevo medio de interacción humana de indudable interés para la Geografía por diferentes motivos que van desde su reconocida capacidad para desbordar las distancias físicas a su singular estructura empresarial, verdadero oligopolio controlado por unas pocas megaempresas globales, pasando por su indiscutible efecto desequilibrador sobre las trayectorias económicas de los territorios y las sociedades. En este sentido, no hay que olvidar que el acceso al Tercer Entorno no está ni mucho menos universalizado, ni 
siquiera en los países más avanzados, dándose el caso de naciones que no cuentan con ningún servidor de Internet o de otras cuyos ciudadanos tienen prohibido el acceso a la Red (Grant, 2000).

En el contexto de esta Ponencia, el interés primordial del Tercer Entorno deriva de su condición de espacio informacional. En otras palabras, Internet constituye una gigantesca oportunidad para acumular información de interés en Geografía Industrial. Quiere esto decir que Internet no es una fuente en sí misma, como a veces tendemos a imaginarla por reducción, sino una vía, un recurso, un medio de acceso a fuentes de información en formato digital. Quienes practicamos esta disciplina debemos, pues, aprender a desenvolvernos en el nuevo ecosistema del Tercer Entorno de la misma forma en que hemos adquirido habilidades y rutinas que nos permiten extraer información útil en E1 y E2 mediante el trabajo de campo, la realización de entrevistas personales, el envío de cuestionarios escritos o la consulta de las fuentes estadísticas publicadas. Este proceso de aprendizaje tiene lugar, por lo común, de manera interactiva y colectiva, beneficiándonos cada uno de nosotros de los conocimientos que nuestros colegas adquieren y ponen a disposición de la comunidad universitaria en los diversos foros de encuentro disciplinar y también en los apartados metodológicos de sus publicaciones.

En realidad, la mecánica del aprendizaje en el Tercer Entorno no difiere sustancialmente de la que opera en el mundo tangible. Es más, dada la inmensidad de la Red, compuesta por unos tres mil millones de páginas (finales de 2000) y un crecimiento de cinco mil nuevos sitios por minuto (Ciberpais Mensual $\mathrm{n}^{\circ} 8$, febrero 2001), es imposible adquirir de forma individual un conocimiento exhaustivo sobre los contenidos potencialmente interesantes para cualquier materia. Los buscadores y las páginas especializadas suponen una ayuda inestimable, pero se limitan a compilar direcciones sin aportar más información adicional. La labor de examen y valoración corresponde, por tanto, al navegante o internauta. Y es aquí donde, de nuevo, las redes de cooperación académica propician el intercambio desinteresado de consejos y direcciones con información relevante. Esta parte de la Ponencia pretende precisamente contribuir a este aprendizaje colectivo en el que todos nos hallamos embarcados y que, de antemano, debemos entender como un proceso en curso permanente e inacabable, nunca como un camino con parada y final en estación-término.

Ante todo, debemos preguntarnos qué tipo de información proporciona Internet. La respuesta es bien sencilla, aunque pueda parecer chocante: en esencia, la misma que los otros dos entornos. Lo que cambia es la facilidad, rapidez y comodidad del acceso, que permite acumular más cantidad de información con menor coste y en menor tiempo. Reflexionemos un poco sobre esta aparente paradoja.

- Mediante el trabajo de campo y el reconocimiento territorial, conocemos el número de empresas de un espacio industrial determinado, su aspecto físico y su disposición sobre el terreno. Internet nos permite conocer cuántas empre- 
sas operan en el ciberespacio, qué imagen virtual ofrecen al navegante y cómo se manifiestan o emplazan en este entorno: de forma individual (empresas .com o es) o agrupadas en páginas colectivas e institucionales (de asociaciones sectoriales o territoriales, de Cámaras de Comercio, de servidores particulares...). Ciertamente, no todas las empresas participan en el Tercer Entorno de forma activa a través de una página propia o colectiva, pero los directorios disponibles en forma de bases de datos informan de la existencia de toda empresa legalmente constituida (véase owww.camerdata.es).

- Gracias a las entrevistas personales accedemos a informaciones más cualitativas sobre la actividad de la empresa, su historia, su percepción de la realidad del sector o del lugar, por no hablar de su discurso corporativo. Toda esta información está sujeta siempre a las restricciones y prejuicios de nuestros interlocutores, que cuentan lo que consideran oportuno y se reservan lo que entienden como confidencial. Lo mismo sucede con las páginas corporativas que cuelgan las empresas en la Red. Al margen de los servicios que puedan prestar a sus clientes, las empresas construyen su propia imagen en la Red y ofrecen en ella la información más conveniente para sus intereses particulares, de modo que los datos cuantitativos y cualitativos que podamos extraer del telediálogo con estas páginas corporativas desde nuestro ordenador serán el fruto de la voluntad explícita de la empresa. Por otra parte, en el mundo sólido el encuentro personal proporciona al investigador información adicional de carácter no verbal, que en el mundo virtual se corresponde con la percepción que obtenemos sobre la comodidad y versatilidad del manejo de la página en cuestión. Más o menos lo mismo sucede con otras organizaciones habituales en la nómina de interlocutores de la Geografía Industrial actual, como los institutos tecnológicos, las asociaciones empresariales, los sindicatos o los gobiernos locales y regionales.

- Por último, buena parte de las fuentes estadísticas de uso ordinario en Geografía Industrial están disponibles en Internet. Es aquí, quizá, donde los avances telemáticos se han dejado notar con mayor intensidad en términos de ahorro de costes y de tiempo, dada la tendencia a la gratuidad de las consultas. Además, los bancos de datos estadísticos permiten completar las series disponibles en las bibliotecas universitarias, tanto hacia atrás como en lo referido a las últimas novedades. Otra de las ventajas tradicionales de este formato es la posibilidad de procesamiento casi inmediato de la información obtenida gracias a las opciones de descarga de ficheros desde los ordenadores-cliente. Lo mismo sucede con los datos informatizados que facilitan algunas de las instituciones que carecen de servicios de información telemática, caso del Registro de Establecimientos Industriales.

Los siguientes epígrafes profundizan en esta triple dimensión informativa que proporciona Internet: localización de empresas (trabajo de campo), toma de contacto con 
interlocutores sociales, políticos y económicos (investigación cualitativa) y, por último, acceso a bancos de datos estadísticos (investigación cuantitativa). Ni que decir tiene que, en este campo, toda pretensión de exhaustividad es fútil, de modo que nos limitaremos a mencionar las direcciones que hemos considerado más relevantes y de funcionamiento más práctico.

\subsection{Internet como apoyo para el trabajo de campo}

Con frecuencia, nuestra investigación comienza por preguntarse por el número y tipo de empresas industriales que operan en un lugar concreto (municipio, comarca, región), o bien por el conjunto de firmas que integran un sector productivo determinado. Las Páginas Amarillas (www.paginas-amarillas.es) permiten búsquedas de esta naturaleza a escala nacional, proporcionando la información básica (nombre, dirección postal y, en su caso, dirección URL). Como hemos dicho ya, el Consejo Superior de Cámaras de Comercio, a través de su banco de datos Camerdata (www.camerdata.es), pone a nuestra disposición la relación completa de empresas que pagan el Impuesto de Actividades Económicas (esto es, todas las del país), con la posibilidad de hacer preguntas sectoriales y territoriales muy precisas. La información básica (nombre, dirección y actividad de la empresa) es gratuita, mientras que los informes comercial y financiero deben ser abonados. La Dirección General de la Pequeña y Mediana Empresa (www.ipyme.org) proporciona acceso al banco de datos InfotelDun \& Bradstreet, elaborado a partir del Registro Mercantil y que incorpora unas 400.000 empresas españolas. A esta misma información se puede acceder desde la página principal del diario El Paús (www.elpais.es): en ambos casos, es preciso abonar una cuota de acceso, aunque permiten visitas guiadas de demostración.

Estas fuentes nos informan sobre el volumen de empresas que operan en el espacio real. No todas lo hacen en el Tercer Entorno, pero sí muchas de ellas, cuyas direcciones virtuales pueden encontrarse, por ejemplo, en el buscador Yahoo! (www.yahoo.com), cuyo apartado sobre economía incluye distintos epígrafes de tipo sectorial con direcciones de empresas. Otro buscador célebre y muy potente, Google (www.google.com) puede encontrar direcciones a condición de conocer el nombre de la empresa o de ser capaz de articular una secuencia de palabras clave dotada del suficiente sentido que incluya empresa, sector y localización. Recientemente, también ha incorporado la clasificación temática.

En ocasiones, sin embargo, deseamos ir más allá. Las empresas no interesan sólo como unidades de una población estadística, sino que puede merecer la pena conocer su implicación en proyectos innovadores, por ejemplo, por mencionar una línea de trabajo especialmente relevante y actual dentro de la Geografía Industrial. El Centro de Desarrollo Tecnológico e Industrial (www.cdti.es) informa, previa inscripción gratuita, sobre las empresas que participan en algún programa público de I+D, 
ofreciendo una completa ficha de cada una que incluye los datos clásicos, junto con otros como la facturación total, o el número de personas y el presupuesto dedicados a I+D. Para los programas comunitarios de investigación y desarrollo disponemos de idéntica información en www.cordis.lu, lo que permite conocer qué empresas españolas desarrollan su labor de innovación tecnológica en cooperación con socios de otros países de la Unión Europea.

Esta atención especial a una dimensión específica de la actividad industrial no tiene por qué ceñirse simplemente a cuestiones temáticas (caso de la innovación), sino que también podemos recurrir a la Red para avanzar en el estudio de sectores concretos, a nivel nacional o regional. La página de Alimarket (www.alimarket.es), consultora especializada en el sector de alimentos y bebidas, también ofrece previo pago una completa información sobre este tipo de empresas: ventas, exportaciones y empleo (fijo y eventual) son algunas de las variables que acompañan a las de localización geográfica.

\subsection{Internet y el acceso a la información cualitativa.}

Una vez conocidas las empresas que se localizan en un espacio determinado o integran un sector específico, el segundo paso en nuestra metodología de investigación consiste en tomar contacto con ellas a fin de obtener más información, lo que nos permite, a su vez, formarnos una idea más cabal del sector en que compiten y del territorio en que se desenvuelven.

Como hemos indicado, cada empresa construye su imagen en el Tercer Entorno a través de su página web, donde ofrece la información que considera más adecuada para sus intereses y, en muchos casos, incluye la posibilidad de adquirir sus productos y la prestación de servicios a sus clientes. De hecho, existen ya trabajos académicos (Escribano, García y Fernández, 1999) que ofrecen a las empresas una guía de criterios para la evaluación de la calidad de sus páginas web, igual que hacen con otros productos y servicios que les suministran sus proveedores o que elaboran sus departamentos corporativos especializados. La página web se convierte así en una fuente de información de primordial interés para la Geografía Industrial cuando trabajamos con un conjunto relativamente limitado de empresas y podemos detenernos en examinar su tele-emplazamiento y su tele-representación.

Desde la perspectiva del investigador, la cuestión radica en el manejo de unos criterios rigurosos y bien articulados internamente para llevar a cabo ese examen o evaluación. Naturalmente, los objetivos concretos de cada investigación orientarán en gran medida la relación de criterios: no es lo mismo estudiar la división del trabajo entre los establecimientos de las grandes multinacionales del automóvil que estudiar la implantación del comercio electrónico entre los pequeños productores artesanos 
de una comarca serrana marginal y periférica. También los presupuestos epistemológicos condicionan el análisis de una web: desde una lógica postestructuralista se prestará atención muy especial a los textos y al discurso gráfico, a lo representacional, mientras que desde posturas más realistas se intentará trascender la textualidad para buscar los contenidos con los que ratificar, perfeccionar o refutar las hipótesis y las teorías con las que se intenta explicar o interpretar la realidad.

Intentando trascender estos factores que impiden la elaboración de una relación de criterios de validez universal, nos atrevemos a proponer aquí un esbozo de guía de evaluación de páginas web de empresas industriales en función de los temas que suscitan más interés para la Geografía Industrial contemporánea.

- Tipo de dirección electrónica: a priori, puede sugerirse la hipótesis de que las empresas con dominio propio (.com, net, .es) conceden más importancia a la acción en el Tercer Entorno que las que se alojan en servidores ajenos y tienen direcciones largas y complicadas.

- Naturaleza de los contenidos: las empresas que simplemente ofrecen información están menos implicadas en el Tercer Entorno que las que permiten a los navegantes formular sugerencias, pedir información o, por supuesto, adquirir los productos o servicios de la empresa.

- Tipo de información: es normal encontrar información sobre las características de la empresa, bien de tipo cuantitativo (ventas, plantilla, resultados) o cualitativo (mercados de venta, galardones recibidos, certificados de calidad, esfuerzo innnovador, compromiso mdioambiental). La información más extensa, no obstante, es la referida a los productos de la empresa, normalmente bien detallados e ilustrados con imágenes. También se incluyen datos sobre la localización de la empresa y sus filiales, caso de haberlas, o de sus puntos de venta y canales de distribución, en caso de que la empresa no practique el comercio electrónico.

- Presencia de enlaces: lo normal es que las empresas no ofrezcan enlaces con otras firmas del mismo sector por razones obvias. Otra cuestión es la de los enlaces con empresas del mismo grupo si operan en sectores diferentes: la presencia de estos enlaces indicaría un sentido de grupo empresarial mayor que su ausencia. Otra posibilidad es la presencia de enlaces con organizaciones sectoriales o territoriales a las que pertenezca la empresa, lo que reflejaría una percepción positiva sobre la acción que desarrollan estos órganos colectivos. La ausencia total de enlaces puede ser un indicio de tenclencias individualistas en la concepción y gestión de la empresa.

- Implicación de la empresa con su entorno geográfico: la oferta de enlaces hacia direcciones turísticas o institucionales locales refleja una valoración positiva de 
la interacción entre empresa y territorio. Los textos de la página de la empresa pueden también incluir referencias de este tenor que no debemos pasar por alto.

- Idiomas: si la página ofrece información en diferentes idiomas, es de suponer que tenga interés en promocionarse más allá de las fronteras nacionales.

La labor de tele-entrevista a las empresas puede completarse con la información recabada a través de las páginas web de otros agentes políticos, sociales y económicos: gobiernos regionales, agencias de desarrollo regional, diputaciones provinciales, ayuntamientos, asociaciones empresariales, sindicatos, institutos y parques tecnológicos, universidades... disponen de sitios en Internet que pueden utilizarse para muy distintos propósitos desde la Geografía Industrial. Además de los buscadores ya mencionados, que tienen información por áreas geográficas, la página del Ministerio de Administraciones Públicas (www.map.es) ofrece enlaces a los organismos públicos. Desde las páginas de las Comunidades Autónomas puede accederse a sus agencias de desarrollo, donde pueden conocerse las líneas de actuación prioritaria y, en ocasiones, datos concretos de carácter estadístico. La página del Ministerio de Educación, Cultura y Deporte (www.mecd.es) contiene enlaces con todas las Universidades, algunas de las cuales incluyen la relación de proyectos de investigación y contratos con empresas en curso. Las asociaciones empresariales no siempre cuentan con página de Internet, sobre todo en el caso de las más especializadas, pero sí disponen de ella las de mayor envergadura (www.ceoe.es), con enlaces a las páginas de sus miembros. La Federación Española de Entidades de Innovación y Tecnología (www.fedit.es) nos permite acceder a las direcciones de todos los institutos tecnológicos, además de ofrecer información sobre las actividades de cada uno de ellos y la posibilidad de descargar documentos técnicos sobre la innovación. La Asociación de Parques Tecnológicos Españoles (www.apte.org) ejerce idéntica función.

La valoración de las páginas web de este tipo de agentes colectivos no puede seguir íntegramente la guía esbozada para las empresas, sino que debe adaptarse en cada caso con interrogantes y criterios relacionados con la manera en que la web se aprovecha (o no) para desempeñar los cometidos que tiene encomendada cada organización, en el caso de las más comprometidas con la actividad industrial, o para prestar servicios útiles a las empresas, en el caso de instituciones con funciones y competencias más amplias.

\subsection{Internet y la información estadística}

Ya se ha dicho que en este terreno se han registrado los mayores avances en el aprovechamiento de las potencialidades de Internet como vía de acceso a la información de interés para la Geografía Industrial. Por el mismo motivo, la comunidad geográfica ha iniciado su aprendizaje y aclimatación al nuevo entorno por este flanco, 
ayudados sus miembros por la propia organización interna y externa de los servidores estadísticos.

En efecto, la página del Instituto Nacional de Estadistica de España (www.ine.es) representa un excelente punto de acceso a la información estadística a todas las escalas geográficas. El perfeccionamiento de su gestión interna es continuo y se plasma en la acumulación de los registros existentes en la base de datos TEMPUS y la agregación de los nuevos en INEbase, cuya consulta resulta sencilla y rápida y ofrece mayor versatilidad que la versión convencional en papel. A esta cualidad, de por sí muy relevante, hay que añadir una no menos reseñable en el Tercer Entorno: la abundancia de enlaces bacia otros servidores estadísticos, tanto españoles (de las Comunidades Autónomas), como extranjeros (bien nacionales o de organismos internacionales). Desde nuestro INE podemos acceder a toda clase de estadísticas siguiendo caminos que cada uno explorará según sus necesidades: aquí nos limitamos a recomendar un punto de partida para tales itinerarios.

También hay que hacer mención de la disponibilidad en Internet de algunas fuentes clásicas de la Geografía Económica y Regional española, como son la Renta Nacional de España y su Distribución Provincial, de la Fundación BBV (www.fbbv.es) y los actuales Anuario Económico de España y Anuario Social de España, editados por La Caixa (www.portal.lacaixa.es) tras recoger el testigo del Anuario del Mercado Español que publicó BANESTO hasta 1993.

\section{Otras fuentes gráficas}

Antes de terminar, conviene mencionar las escasas posibilidades de recurrir a fuentes de carácter cartográfico. La publicación en 1962 del Atlas Industrial de España, editado por el Consejo Superior de Cámaras de Comercio, representa un hito aislado que sólo ha encontrado cierta continuidad en fechas muy próximas. Nos referimos al reciente Atlas elaborado en la Universidad de Oviedo por Fernández Cuesta y Fernández Prieto (1999). En esta línea habría que citar también el volumen correspondiente al sector industrial dentro del Atlas Nacional de España, publicado por el Instituto Geográfico Nacional.

Por otro lado, debemos reconocer las posibilidades que la fotografía aérea entraña para el estudio de cuestiones de localización y ordenación del espacio industrial. Tema poco tratado entre nosotros en los últimos años y que podría explotarse más en combinación con los estudios industriales de carácter local vinculados a la geografía urbana y social. 
Algunas comunicaciones presentadas a esta ponencia ilustran las posibilidades de aplicación de los sistemas de información geográfica a la ordenación del territorio y al papel que en ella desempeña el espacio industrial. Aquí el geógrafo económico tendrá que hacer un esfuerzo de aprendizaje y formación que le permita utilizar estos métodos en sus investigaciones.

\section{El futuro de las fuentes de información en Geografía Industrial}

El uso reciente de las fuentes de información en Geografía Industrial viene marcado por la confluencia de tres tendencias:

- La utilización de las fuentes estadísticas para situar la relevancia de las cuestiones que se investigan en el plano empírico. En el panorama de las preocupaciones actuales de la disciplina, las estadísticas proporcionan un marco de referencia, pero no se utilizan para analizar las relaciones causales porque su contenido y estructuración interna resultan inadecuados.

- La aplicación de métodos cualitativos para superar estas carencias y desentrañar la compleja red de procesos, conexiones, estrategias y experiencias que, invariablemente, está detrás de los fenómenos de desarrollo (o declive) industrial y de la consiguiente configuración de espacios emergentes (o regresivos).

- La relevancia de Internet como nuevo medio de acceso a la información cuantitativa y cualitativa.

Augurar tendencias de futuro es tan atrevido como intentar vaticinar el destino venidero de la Geografía Industrial, por cuanto que las técnicas y fuentes utilizadas responden, en realidad, al programa de investigación dominante en cada etapa histórica de su desarrollo disciplinar. En estos momentos, el desafío que el postestructuralismo viene lanzando a las concepciones tradicionales de la Geografía Económica, en general implica un empleo aún más intensivo de las fuentes cualitativas como fórmula para incorporar a los textos académicos la voz y las vivencias de todos los grupos sociales y económicos implicados en los fenómenos y procesos considerados (Gibson-Graham, 2000). La polifonia (Hughes, 1999) que los autores postmodernos invocan como nuevo método para construir y elaborar los trabajos geográficos coloca a la entrevista semiestructurada como técnica aventajada, máxime si tenemos en cuenta que también los partidarios del realismo (Sayer, 1982; Pratt, 1995), opuestos a los anteriores, se decantan por la entrevista como instrumento central de su opción epistemológica por su capacidad para mostrar las conexiones causales entre los elementos estructurantes de la realidad geográfica. 
A su vez, postmodernismo y realismo se declaran contrarios a las filosofías positivistas que apoyan sus conclusiones en la recogida extensiva de datos cuantificables y susceptibles de tratamiento por procedimientos estandarizados. Las fuentes estadísticas, pues, pueden quedar relegadas a la condición de materia prima con la que dibujar el telón de fondo sobre el que ubicar después a empresas, sindicatos, administración, consumidores y asociaciones de todo tipo, auténticos agentes protagonistas de la vida geoeconómica y objetivo principal de la Geografía Industrial cualitativa.

El más que previsible desarrollo de Internet puede convertir al Tercer Entorno en la vía de acceso primordial a los bancos de datos estadísticos en detrimento de las publicaciones tradicionales, más costosas para el organismo productor y para los clientes, si bien la libertad actual de acceso puede verse en un futuro restringida al pago de una cantidad de dinero. A la vez, las auto-representaciones que, en forma de páginas web, diseñan los agentes económicos para habitar en Telépolis se deben convertir, por fuerza, en objeto de estudio y fuente de información. Los Sistemas de Información Geográfica pueden contribuir a esta representación virtual de la realidad geográfica. La Geografía Industrial del siglo xxi debe habituarse, por tanto, a actuar en los tres entornos: naturaleza, ciudad y ciberespacio.

\section{Notas}

1 Este artículo forma parte de los primeros resultados del proyecto de investigación "Redes y procesos de innovación en las zonas de especialización vinícola de Castila y León: hacia la formación de un entorno innovador", financiado por el Programa Nacional de Promoción General del Conocimiento (referencia : BSO-2000-1422-C09-01), Ministerio de Ciencia y Tecnología.

2 El Profesor Manuel de Terán Álvarez, por ejemplo, en el capítulo dedicado a la Industria en la Geografia Regional de España, (Ariel, 1978), tan sólo identifica con fecha anterior al inicio del primer Plan de Desarrollo (1964) tres trabajos en los que el termino industria figure en el título. Pero incluso en los países más avanzados como Estados Unidos o Francia, autores como A. Pred o P. George, presentan un balance muy insatisfactorio de los estudios en Geografía Industrial, como ha señalado J. Ortega (1977).

3 En su trabajo La Geografía Industrial en España, I Jornadas de Geografía Industrial, Madrid 1987, la Prof $^{a}$. I. Caravaca ofrece una documentada valoración de la trayectoria seguida por los estudios sobre esta rama de la Geografía en el país de 1940 a 1980.

4 En las páginas 354-358 de su Ponencia, hace una sugerente valoración de las posibilidades que se van abriendo a la investigación en Geografía Industrial con la aparición de nuevas fuentes estadísticas así como pone de manifiesto las limitaciones que pueden presentar en función de la escala territorial o en cuanto al grado de desagregación de grupos de actividades.

5 ONUDI: Organización de las Naciones Unidas para el Desarrollo Industrial.

6 CEPAL: Comisión Económica para América Latina; ALADI: Asociación Latinoamericana de Integración; SELA: Sistema Económico Latinoamericano; MCCA: Mercado Común Centroamericano; CARICOM: Mercado Común Caribeño.

7 Recientemente se han emitido mensajes desde la Administración Central en el sentido de su posible supresión que, de concretarse, privaría a los investigadores de una valiosa fuente de escala local. 


\section{Bibliografía}

Barral, L. M. (1998): "El empleo de grupos de discusión en la investigación social». En García Ballesteros, A. (coord.): Métodos y técnicas cualitativas en geografia social. Barcelona: Oikos-Tau, pp. 61-84.

Bailly, A. (1998): "Los indicadores sociales: medidas objetivas de las ciencias duras en las evaluaciones subjetivas de las ciencias blandas". En Garcia Ballesteros, A. (coord.): Métodos y técnicas cualitativas en geografia social. Barcelona: Oikos-Tau, pp. $45-52$

Benito, P. y Pascual, H. (1998): Geografia y geógrafos industriales en España. Sevilla: Instituto de Fomento de Andalucía.

Blanchet, A. y otros (1989): Técnicas de investigación en ciencias sociales. Madrid: Ed. Narcea.

Caravaca, I. (1987): "La Geografia Industrial en España". I Jornadas de Geografia Industrial. Madrid: Grupo de Geografía Industrial (policopiado).

Delgado, J. M. y Gutiérrez, J. (coords.) (1995): Métodos y técnicas cualitativas de investigación en ciencias sociales. Madrid: Síntesis.

Echeverría, J. (1994): Telépolis. Barcelona: Destino.

Echeverría, J. (1995): Cosmopolitas domésticos. Barcelona: Anagrama.

Echeverría, J. (1999): Los Señores del Aire. Telépolis y el Tercer Entorno. Barcelona: Destino.

Escribano, J. J., García, Ma . L. y FERNÁNDEZ, L. (1999): "Los controles de calidad en la web. Economia Industrial $n^{\circ} 326$, pp. 123-137.

Eyles, J. (1998): "Los métodos cualitativos en la geografía humana: bases teóricas y filosóficas y aplicaciones prácticas". En García Ballesteros, A. (coord.): Métodos y técnicas cualitativas en geografia social. Barcelona: Oikos-Tau, pp. 33-44.

Fariñas, J.C. y Jaumandreu, J. (1994): "La encuesta sobre estrategias empresariales: características y usos". Economia Industrial $\mathrm{n}^{\circ} 299$, pp. 109-120.

Feito, J.M. (1994): "El papel de la nueva encuesta industrial de empresas en la investigación estadística del sector industrial. Economía Industrial $\mathrm{n}^{\circ} 299$, pp. 103-108.

Fernández, G. y Fernández, J. R. (1999): Atlas industrial de España. Desequilibrios territoriales y localización de la industria. Ed. Nobel, Oviedo.

Ferrer, M. (1975): "Espacios industrializados en España. Áreas y regiones industriales». En Ciudad e Industria. Actas del IV Coloquio sobre Geografia. Oviedo: Asociación de Geógrafos Españoles, pp. 341-364.

García, A. (coord.) (1998): Métodos y técnicas cualitativas en geografia social. Barcelona: Oikos-Tau.

Gibson-Graham, J.K. (2000): "Poststructural Interventions". En Sheppard, E. y Barnes, T. J. (eds.): A Companion to Economic Geography. Londres: Basil Blackwell, pp. 95-110.

Gómez, J. y otros (1988): Viajeros y paisajes. Madrid: Alianza Editorial.

Grant, R. (2000): “The Economic Geography of Global Trade. En Sheppard, E. y Barnes, T. J. (eds.): A Companion to Economic Geograpby. Londres: Basil Blackwell, pp. 411-431.

Healey, M. I. y Rawlinson, M. B. (1993): "Interviewing Business Owners and Managers: a Review of Methods and Techniques". Geoforum vol. 24, pp. 339355.

Hughes, A. (1999): "Constructing Economic Geographies from Corporate Interviews: 
Insights from a Cross-Country Comparison of Retailer-Supplier Relationships". Geoforum vol. 30, pp. 363-374.

Información comercial española $\mathrm{n}^{\circ} 752$. Número Monográfico sobre Estadisticas españolas del sector exterior. 1996.

Mallart i Casamajor, Ll. (1997): Viaje y geografia. La preparación de un viaje de estudio. Barcelona: Oikos-Tau.

Manero, F. (1992): "Los estudios de Geografía Industrial en España: expansión reciente y principales líneas de investigación. En Real Sociedad Geográfica y Asociación de Geógrafos Españoles: La Geografía Española (1970-1990). Aportación Española al XXVII Congreso de la Unión Geográfica Internacional. Madrid: Fundación BBV, pp. 171-174.

Méndez, R. (1992): "La Geografía Industrial en la reactivación de los estudios sobre industria y territorio" En Real Sociedad Geográfica y Asociación de Geógrafos Españoles: La Geografia Española (1970-1990). Aportación Española al XXVII Congreso de la Unión Geográfica Internacional. Madrid: Fundación BBV, pp.174-181.

Moreno, A. (1994): "La difusión de estadísticas en soporte electrónico. Panorama e implicaciones para la geografía. Estudios Geogräficos no 214-217, pp. 544-554.

Oinas, P. (1999): "Voices and Silences: the problem of Access to Embeddedness". Geoforum vol. 30, pp.351-361.

Ortega, J. (1975): «Actividad industrial y espacio industrial como objeto de la Geografiam. En Ciudad e Industria. Actas del IV Coloquio sobre Geografía. Oviedo: Asociación de Geógrafos Españoles, pp. 18-32.

Portela, P. (dir.) (1996): Directorio de fuentes de información de la economía española. Madrid: Crítica.

Pratt, A.C. (1995): "Putting Critical Realism to Work: the Practical Implications for
Geographical Research.. Progress in Human Geography vol. 19, pp. 61-74.

Redondo, A. (1998): "Las encuestas y las entrevistas en las investigaciones geográficas". En García BAllesteros, A. (coord.): Métodos y técnicas cualitativas en geografia social. Barcelona: Oikos-Tau, pp. 53-60.

Revilla, P. (1994): "La modernización de las estadísticas industriales. Hacia un sistema integrado de encuestas". Economía Industrial $\mathrm{n}^{\circ} 299$, pp. 87-102.

Revista Fuentes Estadísticas: www.fuentesestadisticas.com

Rodríguez, R. y Villarino, M. (coords.) (1988): Actas de las II Jornadas de Geografia Industrial. Santiago de Compostela: Grupo de Geografía Industrial (AGE).

Ruiz de Olabuénaga, J. I. (1996): Metodología de la investigación cualitativa. Bilbao: Ediciones Universidad de Deusto.

Ruiz de Olabuénaga, J. I. e Ispizúa, $M^{a}$. A. (1989): La descodificación de la vida cotidiana. Métodos de investigación cualitativa. Ediciones Universidad de Deusto. Bilbao.

Sayer, A. (1982): "Explanation in Economic Geography: Abstraction versus Generalization. Progress in Human Geography vol. 6, pp. 68-88.

Situación n. ${ }^{\circ}$ 3-4/92: Número monográfico sobre La estadistica en España boy, 1992.

Taylor, S.J. y Bogdan, R. (1996): Introducción a los métodos cualitativos de investigación, Barcelona: Paidós.

Terán, M. de (1978): "Industria”. En Geografía Regional de España. Barcelona: Ariel, pp. 382-455.

Vallés, M.S. (1999): Técnicas cualitativas de investigación social: reflexión metodológica y práctica profesional. Madrid: Sintesis, $2^{\mathrm{a}}$. ed. 


\section{Anexo de páginas web de interés para las fuentes en Geografía Industrial}

\section{A. Fuentes estadísticas}

\section{Titular: Banco Mundial}

- Dirección electrónica: www.bancomundial.org

- Idioma(s): español - inglés - francés - ruso - portugués - japonés

- Principales contenidos: informes sobre las actividades del Banco y abundantes documentos y datos estadísticos

- Descarga de información: Sí

- Enlaces: a otras instituciones del Grupo del Banco Mundial y a otros organismos internacionales relacionados con la promoción del desarrollo económico y social sostenible.

Titular: Organización de las Naciones Unidas

- Dirección electrónica: www.un.org

- Idioma(s): español - inglés - francés - ruso - árabe - chino

- Principales contenidos: documentos propios y bases de datos estadísticas sobre economía internacional y sobre los países del mundo

- Descarga de información: Sí

- Enlaces: a todos los servidores estadísticos de organismos internacionales y de países del mundo. Acceso a Organización Mundial del Comercio (www.wto.org), Organización de las Naciones Unidas para el Desarrollo Industrial (www.unido.org), Organización de las Naciones Unidas para el Comercio y el Desarrollo (www.unctad.org), Organización Mundial del Trabajo (www.ilo.org), Organización Mundial para la Agricultura y la Alimentación (www.fao.org) y las distintas comisiones económicas regionales: todas ellas ofrecen acceso y descarga de documentos y estadísticas. 
Titular: Programa de Naciones Unidas sobre Desarrollo Humano

- Dirección electrónica: www.undp.org/hdro

- Idioma(s): inglés

- Principales contenidos: Informe Anual sobre Desarrollo Humano (año en curso y años anteriores) y datos estadísticos anejos.

- Descarga de información: Sí

- Enlaces: No

Titular: Organización para la Cooperación y el Desarrollo Económico

- Dirección electrónica: www.oecd.org

- Idioma(s): inglés - francés

- Principales contenidos: documentos propios, estudios de países y datos estadísticos

- Descarga de información: Sí

- Enlaces: No

Titular: EUROSTAT. Oficina Estadistica de las Comunidades Europeas

- Dirección electrónica: europa.eu.int/comm/eurostat

- Idioma(s): los once principales de la Unión Europea

- Principales contenidos: estadísticas sobre los países comunitarios y sus regiones, así como documentos sobre todos los aspectos de la Unión.

- Descarga de información: Sí

- Enlaces: No

Titular: Inforegio. Dirección General XVI de la Comisión Europea

- Dirección electrónica: www.inforegio.cec.eu.int/dg16_es.htm 
- Idioma(s): español - inglés - francés - alemán - italiano

- Principales contenidos: reglamentos, programas y resultados de la política regional europea, documentos de trabajo, series de mapas y gráficos

- Descarga de información: Sí

- Enlaces: a otros sitios del servidor de la Unión Europea relativos a la acción regional

Titular: Instituto Nacional de Estadística

- Dirección electrónica: www.ine.es

- Idioma(s): español - inglés

- Principales contenidos: datos estadísticos y metodología de elaboración

- Descarga de información: Sí

- Enlaces: a todos los servidores estadísticos de las Comunidades Autónomas españolas, a todos los servidores estadísticos oficiales de los distintos países clel mundo y a organismos económicos internacionales.

Titular: Banco de España

- Dirección electrónica: www.bde.es

- Idioma(s): español - inglés

- Principales contenidos: información estadística y documentos de producción propia

- Descarga de información: Sí

- Enlaces: a organismos económicos internacionales y a servidores estadísticos españoles y extranjeros a través del INE.

Titular: Instituto Español de Comercio Exterior

- Dirección electrónica: www.icex.es 
- Idioma(s): español

- Principales contenidos: bases de datos de empresas y de comercio exterior, documentos técnicos, programas de formación, financiación, cooperación y promoción en materia de comercio exterior

- Descarga de información: Sí

- Enlaces: a páginas de asociaciones empresariales y organismos públicos

Titular: Fundación BBVA

- Dirección electrónica: www.fbbv.es

- Idioma(s): español

- Principales contenidos: datos estadísticos regionales y provinciales de España

- Descarga de información: Sí

- Enlaces: a otras empresas del grupo BBVA

Titular: Servicio de Estudios de La Caixa

- Dirección electrónica: www1.lacaixa.es:8090/webes

- Idioma(s): español - catalán - inglés

- Principales contenidos: Anuarios comercial y social de España; documentos propios sobre temas sociales y económicos

- Descarga de información: Sí

- Enlaces: No

\section{B. Organismos españoles de representación y promoción económica}

Titular: Consejo Económico y Social de España

- Dirección electrónica: www.ces.es

- Idioma(s): español - inglés 
- Principales contenidos: actividades del Consejo, publicaciones, bases de datos bibliográficas sobre economía española

- Descarga de información: Sí

- Enlaces: otros consejos económicos y sociales extranjeros, instituciones españolas de la Administración Central, todas las organizaciones económicas y sociales representadas en el Consejo (patronales, cooperativas, sindicales y de consumidores)

Titular: European Association of Development Agencies (sección España)

- Dirección electrónica: www.eurada.org/Members/Spain/spain.htm

- Idioma(s): inglés - francés

- Principales contenidos: boletín interno, documentos de trabajo

- Descarga de información: Sí

- Enlaces: a todas las agencias europeas de desarrollo regional, incluidas las agencias españolas oficialmente constituidas como tales: Andalucía (www.ifa.es), Aragón (www.iaf.es), Asturias (www.ifrasturias.com), Canarias (www.cistia.es), Cantabria (www.sodercan.com), Castilla y León (www.jcyl.es/ $\mathrm{jcyl} / \mathrm{cict} / \mathrm{ade}$ ), Cataluña (www.gencat.es/cidem), Galicia (www.igape.es), Madrid (www.commadrid.es/imade), Murcia (www.ifrm.es), País Vasco (www.spri.es), Valencia (www.impiva.es)

Titular: Federación Española de Entidades de Innovación y Tecnología

- Dirección electrónica: www.fedit.es

- Idioma(s): español - inglés

- Principales contenidos: relación de centros asociados (con información detallada de cada uno), documentos de trabajo, dossier de prensa sobre innovación y tecnología

- Descarga de información: Sí

- Enlaces: a todos los centros e institutos tecnológicos asociados 
Titular: Asociación de Parques Tecnológicos de España

- Dirección electrónica: www.apte.org

- Idioma(s): español

- Principales contenidos: objetivos de la asociación

- Descarga de información: No

- Enlaces: a todos los parques y organismos miembros de la asociación

Titular: Iniciativa Comunitaria Leader

- Dirección electrónica: www.rural-europe.aeidl.be

- Idioma(s): español - francés - inglés - alemán - portugués - italiano

- Principales contenidos: documentos de trabajo, bases de datos sobre regiones y agentes participantes, acciones innovadoras, normativa vigente

- Descarga de información: Sí

- Enlaces: a organismos europeos y españoles encargados de la iniciativa Leader

Titular: Unidad Española del Observatorio Europeo LEADER

- Dirección electrónica: redrural.tragsatec.es/redruralidefault.htm

- $\operatorname{Idioma(s):~español~}$

- Principales contenidos: objetivos de los programas LEADER y PRODER, acciones en marcha en toda España, revista, documentos de trabajo de jornadas monográficas, foro de debate

- Descarga de información: Sí

- Enlaces: a páginas institucionales y temáticas relacionadas con el desarrollo rural en España y Europa 